\title{
Mid-latitude tropospheric ozone columns from the MOZAIC program: climatology and interannual variability
}

\author{
R. M. Zbinden ${ }^{1}$, J.-P. Cammas ${ }^{1}$, V. Thouret ${ }^{1}$, P. Nédélec ${ }^{1}$, F. Karcher ${ }^{2}$, and P. Simon ${ }^{2}$ \\ ${ }^{1}$ Laboratoire d'Aérologie, UMR5560, Toulouse, France \\ ${ }^{2}$ CNRM, Météo-France, Toulouse, France
}

Received: 21 February 2005 - Published in Atmos. Chem. Phys. Discuss.: 29 July 2005

Revised: 21 October 2005 - Accepted: 2 February 2006 - Published: 31 March 2006

\begin{abstract}
Several thousands of ozone vertical profiles collected in the course of the MOZAIC programme (Measurements of Ozone, Water Vapour, Carbon Monoxide and Nitrogen Oxides by In-Service Airbus Aircraft) from August 1994 to February 2002 are investigated to bring out climatological and interannual variability aspects. The study is centred on the most frequently visited MOZAIC airports, i.e. Frankfurt (Germany), Paris (France), New York (USA) and the cluster of Tokyo, Nagoya and Osaka (Japan). The analysis focuses on the vertical integration of ozone from the ground to the dynamical tropopause and the vertical integration of stratospheric-origin ozone throughout the troposphere. The characteristics of the MOZAIC profiles: frequency of flights, accuracy, precision, and depth of the troposphere observed, are presented. The climatological analysis shows that the Tropospheric Ozone Column (TOC) seasonal cycle ranges from a wintertime minimum at all four stations to a spring-summer maximum in Frankfurt, Paris, and New York. Over Japan, the maximum occurs in spring presumably because of the earlier springtime sun. The incursion of monsoon air masses into the boundary layer and into the mid troposphere then steeply diminishes the summertime value. Boundary layer contributions to the TOC are 10\% higher in New York than in Frankfurt and Paris during spring and summer, and are 10\% higher in Japan than in New York, Frankfurt and Paris during autumn and early spring. Local and remote anthropogenic emissions, and biomass burning over upstream regions of Asia may be responsible for the larger low- and mid-tropospheric contributions to the tropospheric ozone column over Japan throughout the year except during the summer-monsoon season. A simple Lagrangian analysis has shown that a minimum of $10 \%$ of the TOC is of stratospheric-origin throughout the year. Investigation of the short-term trends of the TOC over the period 1995-2001
\end{abstract}

Correspondence to: R. M. Zbinden

(zbir@aero.obs-mip.fr) shows a linear increase $0.7 \%$ year in Frankfurt, $0.8 \%$ year in Japan, 1.1\%/year in New York and 1.6\%/year in Paris for the reduced 1995-1999 period. Dominant ingredients of these positive short-term trends are the continuous increase of wintertime tropospheric ozone columns from 1996 to 1999 and the positive contributions of the mid troposphere whatever the season.

\section{Introduction}

Tropospheric ozone is a trace gas with a large natural variability in space and time and a mixing ratio in the range of about $10-100 \mathrm{ppbv}$. The origin of tropospheric ozone is either in-situ photochemical production or ozone flux transported from the stratosphere. For many years, photochemical air pollution was considered as a problem of mainly local or regional significance, affecting clean air sites by the advection of polluted urban plumes that spread over the countryside. Later on, it was discovered that smog-like reactions associated with the oxidation of methane and other hydrocarbons induced the photochemical production of ozone in the relatively unpolluted troposphere (Crutzen, 1973, 1974). The role of photochemistry in controlling the production of tropospheric ozone was therefore questioned (Chameides and Walker, 1973, 1976). The controversy that arose from proponents of a tropospheric ozone budget dominated by stratospheric-origin downward transport (Fabian, 1974; Chatfield and Harrison, 1976) was anchored in the inability to clarify which, of stratospheric flux or photochemical production, was responsible for the spring-summer lower tropospheric ozone maximum. The quantitative assessment of the cross-tropopause mass fluxes of ozone and other chemical constituents is of major importance for atmospheric chemistry and climate. Regener (1957) and Junge (1962) consider the stratosphere to be the main source from which ozone enters the troposphere via tropopause exchange processes.

Published by Copernicus GmbH on behalf of the European Geosciences Union. 
Ozone is transported from the lower stratosphere into the upper troposphere through tropopause folding (Danielsen et al., $1968,1987)$ and is exchanged with the troposphere via diabatic processes and turbulent diffusion (Lamarque and Hess, 1994), mixing processes and convective erosion during the breakup of stratospheric filaments (Appenzeller et al., 1996; Gouget et al., 2000). Climatological global-scale studies based on trajectory calculations and operational analysis data have been developed in recent years. A method for assessing cross-tropopause fluxes is to identify exchange events, taking into account the history of the potential vorticity along a large set of trajectories. Wernli and Bourqui (2002) introduce a residence-time criterion to distinguish transient and irreversible exchange events, the former only influencing the layers near the tropopause, the latter having the potential to contribute to the tropospheric ozone budget. When this method was applied to one year of operational analyses, the result showed that the seasonal cycle of the zonally integrated cross-tropopause mass flux was downwards in the extratropics with a maximum (minimum) in winter-spring (autumn). In contrast to the net exchange, Wernli and Bourqui (2002) identify a symmetrical up and down exchange that has almost no seasonal variation and a larger amplitude than the net exchange, and is strongly sensitive to the residence time. Concluding on recent Lagrangian studies, Stohl et al. (2003) insist on the importance of separating deep stratospheretroposphere transport from shallow stratosphere-troposphere transport, the former stream contributing less than 5\% of the tropospheric mass at the surface when the residence time criterion is 4 days. Deep stratosphere-troposphere transport has a winter maximum mainly near the Atlantic and Pacific storm track entrance and exit regions, which is, according to Stohl et al. (2003), an indication that it is not the cause of the late springtime maximum of ozone in the lower troposphere. Shallow stratosphere-troposphere transport has a small-amplitude seasonal cycle.

Long time-series of ozone measurements in Europe show that the concentration of ozone has been increasing not only in the air near the Earth's surface ("wet chemical method": Feister and Warmbt, 1987; "Schönbein method": Volz and Kley, 1998), but also in the free troposphere ("ozone balloon soundings": Staehelin and Schmid, 1991; "ground-based UV-photometers": Staehelin et al., 1994; "Schönbein method" and "UV-absorption analyser" Marenco et al., 1994). These results have been taken as evidence of an increase in the photochemical production of ozone in the atmosphere due to the growing emissions of ozone precursors. In the troposphere over Europe, the longest data time series of ozonesondes began in the 1960s at Hohenpeissenberg (Germany) and Payerne (Switzerland). Statistical searches for tropospheric long-term trends applied to this dataset have shown a large increase in tropospheric ozone (in the range of 0.7-1.4\%/year) since the beginning of the 1970s (Logan, 1985; Tia et al., 1986; Staehelin and Schmid, 1991; Harris et al., 1997; Oltmans et al., 1998; Logan, 1994; Weiss et al.,
2001). With regard to the UTLS region, Tarasick et al. (2005) compare overall linear trends for the 1980-1990 and 19912001 periods with Canadian ozonesondedata and show that negative trends for the former period have rebounded to positive trends in the latter period at all levels below $63 \mathrm{hPa}$. These differences do not appear to be related to changes in tropopause height, as the average height of the tropopause did not change over the periods.

Therefore, the global distribution and trends of ozone in the troposphere remain a major focus of interest. Comprehensive and continuous observations are needed to assess ozone's role in climate change. One of the largest ozone databases existing today comes from the MOZAIC programme (Measurements of Ozone, Water Vapour, Carbon Monoxide and Nitrogen Oxides by In-service Airbus Aircraft, Marenco et al., 1998 ${ }^{1}$ ). Using automatic equipment installed on-board five long-range Airbus A340 aircraft flying regularly all over the world, about 46000 vertical profiles of ozone between 0 and 9-12 km altitude and about 23000 time series along inter-continental flight routes have been acquired since 1994. The initial ozone climatology produced in the UTLS domain with the first two years of MOZAIC measurements (Thouret et al., 1998a) compared well with data from the ozone sounding network (Thouret et al., 1998b). A new UTLS ozone climatology, based on the 1994-2003 MOZAIC measurements and referenced to the altitude of the dynamical tropopause, is reported in a companion study (Thouret et al., 2006).

The general aim of this work is to better document the spatial and temporal distribution of tropospheric ozone and its variability in the northern mid-latitudes from a MOZAIC data subset of vertical profiles at some of the most frequently visited airports. The study is orientated towards the seasonal and inter-annual analysis of two vertically integrated quantities, the tropospheric ozone column, which is the integrated ozone profile through the depth of the troposphere, and the stratospheric intrusion ozone column, which is the integrated stratospheric-origin ozone profile through the depth of the troposphere. A Lagrangian method is used to discriminate between stratospheric- and tropospheric-origin ozone below the tropopause. The reasons for studying vertically integrated quantities are: i) to deliver an integrated view of the ozone column in the troposphere, ii) to make meaningful comparisons of ozone columns in the boundary layer, the mid troposphere, and the upper troposphere, iii) to compare the impact of stratosphere-troposphere exchange with that of photochemical sources, iv) to provide meaningful comparisons with present and future satellite retrieval techniques that provide information on the tropospheric ozone column, v) to provide models with seasonal-mean and regional-mean data for initialization. The present MOZAIC dataset allows a limited investigation of the interannual variability of the tropospheric ozone column and also an assessment of its trends

\footnotetext{
${ }^{1}$ http://www.aero.obs-mip.fr/mozaic/
} 
in the short-term (the 7-year period from January 1995 to December 2001 investigated here). From now on, for the sake of brevity, trends in the short-term will be noted simply "trends" as far as the MOZAIC dataset is concerned. The aim is to quantify the Tropospheric Ozone Column (TOC) at northern mid-latitudes, to give an assessment of the contribution of stratospheric-origin air to TOC, and to investigate the interannual variability and the trends of TOC. Section 2 presents the MOZAIC data, Sect. 3 is devoted to definitions and methodology, Sect. 4 is a climatology of TOC, Sect. 5 investigates the trends and the interannual variability of TOC. Finally, we summarize our main results in Sect. 6.

\section{MOZAIC data}

Measurements of ozone in the MOZAIC programme are taken every four seconds from take-off to landing. Based on the dual-beam UV absorption principle (Model 49-103 from Thermo Environment Instruments, USA), the ozone measurement accuracy is estimated at $\pm[2 \mathrm{ppbv}+2 \%]$ (Thouret et al., 1998a). From the beginning of the program in 1994, the measurement quality control procedures have remained unchanged to ensure that long-term series are free of instrumental artefacts. Instruments are laboratory calibrated before and after the flight periods, the duration of which is generally 12 to 18 months. The laboratory calibration is performed with a reference analyzer which is periodically crosschecked at the National Institute of Standards and Technology in France. Additionally during the flight operation period, the zero and for the calibration factor of each instrument is regularly checked using a built-in ozone generator. Furthermore, comparisons are made between aircraft when they fly close in location and time, which happens several times a month. Ozone measurements from the MOZAIC programme were validated by comparisons with the ozone sounding network (Thouret et al., 1998b). In the present study, the measurements used are ascent and descent profiles from August 1994 to February 2002. Raw data (4 s time resolution) are averaged over $150 \mathrm{~m}$ height intervals. To help the interpretation of MOZAIC data, meteorological parameters derived from the operational European Centre for Medium-Range Weather Forecast (ECMWF) analyses and interpolated along aircraft trajectories have been added into the MOZAIC database by Météo-France. These parameters are pressure levels of four Potential Vorticity $(P V)$ values $(1,2,3$ and $4 \mathrm{pvu})$, the $P V$ itself and a potential vorticity reconstructed $(R P V)$ with a Lagrangian method. Details are given in the following section. Table 1 lists all the abbreviations used in the paper. The MOZAIC project began nitrogen oxide measurements (Volz-Thomas et al., 2005) on one aircraft in 2001. Work in progress on these measurements will soon help to understand the budget of tropospheric ozone. Note that there is free access to MOZAIC data for scientists (see the MOZAIC web site http://www.aero.obs-mip.fr/mozaic/).
Table 1. List of used abbreviations.

\begin{tabular}{lll}
\hline Abbreviation & Signification & Comment \\
\hline$R H$ & Relative Humidity & in $\%$ \\
$P V$ & Potential Vorticity & in pvu \\
$R P V$ & Reconstructed Potential Vorticity & in pvu \\
$D T$ & Dynamical Tropopause & - \\
\hline DU & Dobson Unit & - \\
$O L T$ & Ozone Layer Thickness & in DU/150 m \\
$M O C$ & MOZAIC Ozone Column & in DU \\
$T O C$ & Tropospheric Ozone Column & in DU \\
$T O R$ & Tropospheric Ozone Residuals & in DU \\
& & (Creilson et al., 2003) \\
$d T O C$ & Deseasonalized TOC & in DU \\
$P T O C$ & Pure Tropospheric Ozone Column & in DU \\
SIC & Stratospheric Intrusion Column & in DU \\
\hline$B L$ & Boundary Layer & from ground to $2 \mathrm{~km}$ \\
$M T$ & Mid Troposphere & from $2 \mathrm{~km}$ to $8 \mathrm{~km}$ \\
$U T$ & Upper Troposphere & from $8 \mathrm{~km}$ to DT \\
UTLS & Upper Troposphere Low Stratosphere & - \\
STE & Stratosphere Troposphere Exchange & - \\
\hline NAO & North Atlantic Oscillation & - \\
NAM & Northern Annular Mode & - \\
\hline
\end{tabular}

A subset of mid-latitudes MOZAIC sites, having high frequencies of observations and spread over the northern hemisphere, was selected. It comprised: Frankfurt (8.5 E, 50.0 N), with 6338 vertical profiles as two aircraft operate from this airport; Paris $(2.6 \mathrm{E}, 49.0 \mathrm{~N})$, with 3308 vertical profiles; New York (74.2 W, 40.7 N), with 2631 vertical profiles; and the Japanese cluster of Tokyo (139.7E, 35.6 N), Nagoya $(136.8 \mathrm{E}, 35.1 \mathrm{~N})$ and Osaka $(135.0 \mathrm{E}, 34.0 \mathrm{~N})$ with 1899 vertical profiles. The three Japanese cities visited by MOZAIC, all located on the Japanese Pacific coast and separated by at most $400 \mathrm{~km}$, were treated as a single MOZAIC site representing the Japanese region, ensuring a suitable sampling frequency for this region. Profiles were defined as the part of the flight between ground level and the first pressure stabilized cruising level, usually up to about $300 \mathrm{hPa}(200 \mathrm{hPa})$ with regard to the ascent (descent) profile. The ground tracks of the aircraft profiles formed a disk of about $400 \mathrm{~km}$ radius in Frankfurt and Paris, a quarter of a disk facing northeast in New York, and half a disk facing northwest over Japan. We consider aircraft profiles to be as valuable as balloon soundings for the computation of tropospheric ozone columns in spite of the fact that the atmospheric volumes delimited by the ground tracks of the aircraft vertical profiles are somewhat larger than those of balloon soundings, and that the ascent rates are greater for sounding balloons. These discrepancies have been evaluated by Thouret et al. (1998b).

Monthly time series of flight numbers over the 4 MOZAIC sites are displayed on Fig. 1. Frankfurt has the best sampling frequency with an average of 70 profiles per month and minimum monthly numbers exceeding 30 except in $\mathrm{Au}-$ gust 1994 and March 2001. Paris has a good sampling frequency with an average of 36 profiles per month but only 

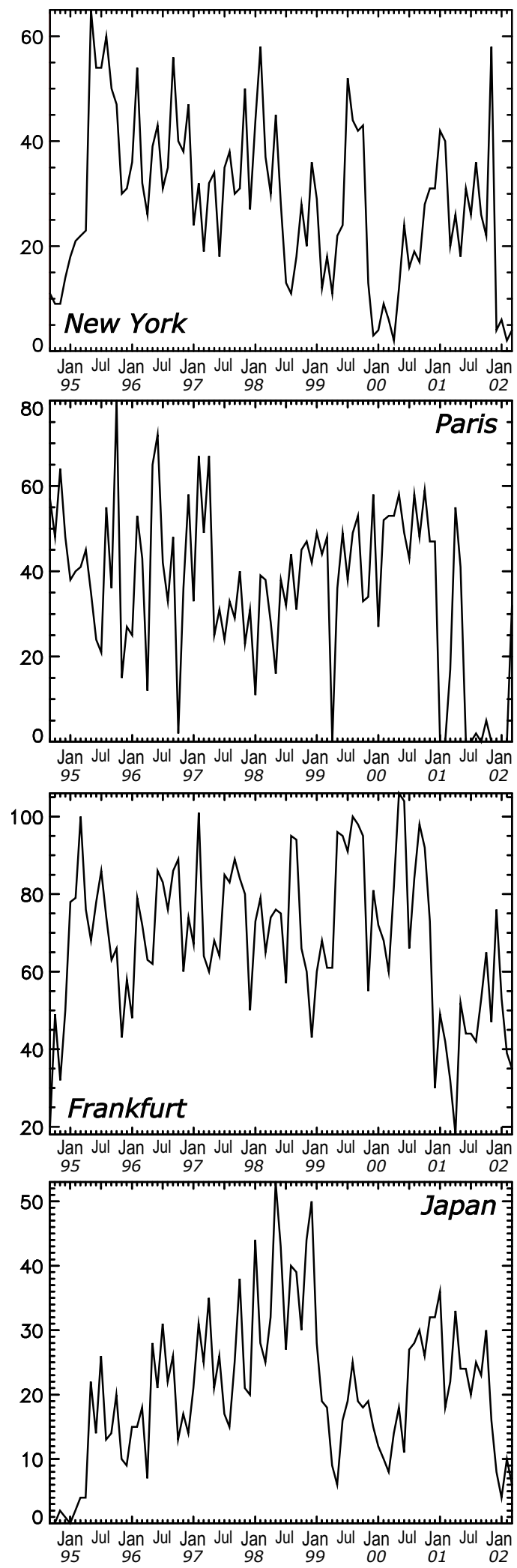

Fig. 1. Number of MOZAIC profiles per month over the 1994-2002 period for New York, Paris, Frankfurt and Japan stations.
2 profiles per month in September 1995, and some periods with none in March 1998, December-January 2000 and May 2001-January 2002. An average of 30 profiles per month is reached in New York but with less than 10 profiles per month in December 1998-March 1999 and in JanuaryFebruary 2002. Japan has an average of 20 profiles per month but less than 5 profiles per month during August 1994-March 1995 and February 2002. Note that the measurement frequency for most of the ozone sounding stations of the northern hemisphere is weekly (WOUDC web site: http://www.nilu.no/niluweb/).

\section{Definitions and methodology}

\subsection{Tropospheric ozone column}

Within the MOZAIC data, it is not always possible to identify the height of the tropopause because the aircraft may not cross the tropopause during the ascent or descent. The criterion on the temperature lapse rate defined by WMO (1957) may be unverifiable because of the insufficient vertical depth sampled by aircraft near the tropopause. Here, we use the definition of the dynamical tropopause (DT) given by Hoskins et al. (1985) which is a potential vorticity surface corresponding to the value 2 pvu (with $1 \mathrm{pvu}=10^{-6} \mathrm{~m}^{2} \mathrm{~K} \mathrm{~s}^{-1} \mathrm{~kg}^{-1}$ ). Potential vorticity was computed from 6-hourly ECMWF analyses with the T213 spectral truncation on the horizontal and with 31 vertical levels. Interpolation into the aircraft' trajectories was performed using a 3-D cubic Lagrange formulation for space and a simple linear formulation for time. In case of multiple intersections of the 2-pvu line with the vertical profile (see Fig. 2 for details), the dynamical tropopause was defined to be where the highest part of the 2-pvu line crossed the vertical profile. We further arbitrarily consider three vertical layers in the depth of the troposphere. The layer from the dynamical tropopause to $8 \mathrm{~km}$ altitude will be referred to as the upper troposphere $(U T)$, the $8-2 \mathrm{~km}$ altitude layer the mid troposphere $(M T)$, and the $2-0 \mathrm{~km}$ altitude layer the boundary layer $(B L)$.

To characterize the vertical distribution of ozone in the troposphere we chose to represent equivalent thicknesses of ozone in $150 \mathrm{~m}$ depth layers along the tropospheric column. In this way, tropospheric ozone columns (TOC) were calculated from the ground to the dynamical tropopause (see Fig. 2). TOC, expressed in Dobson Units $(D U)$, is the equivalent thickness of ozone contained in the tropospheric column compressed down to standard temperature and pressure (Andrews et al., 1987). The contribution to TOC of each $150 \mathrm{~m}$ depth layer of atmosphere is called the Ozone Layer Thickness $(O L T)$, so that $T O C$ is the integration of $O L T$ from ground to $D T$, while the integration of $O L T$ from ground to the top of the MOZAIC vertical profile is called MOC for MOZAIC Ozone Column. The detailed computation of $O L T$ and TOC is given in the Appendix. The purpose of providing 


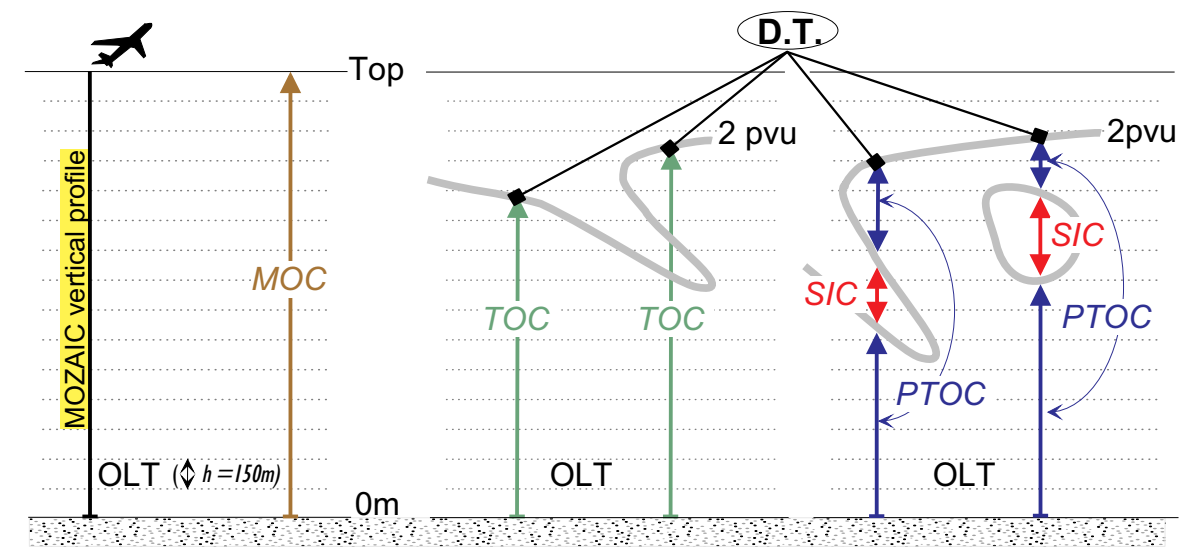

Fig. 2. Schematic definitions: Ozone Layer Thickness $(O L T)$ is the equivalent amount of ozone expressed in DU (see Appendix) for a 150-m deep layer where full-resolution MOZAIC ozone data are averaged. MOZAIC Ozone Column (MOC) is the integrated ozone profile from the ground to the cruise altitude of the aircraft (noted Top). Tropospheric Ozone Column (TOC) is the integrated ozone profile from the ground to the Dynamical Tropopause (DT, black diamond). Coming down from the stratosphere, $D T$ is the first intersection with the 2-pvu contour line. Stratospheric Intrusion Column (SIC) is the integrated ozone profile through layers that fulfil stratospheric-origin criteria below the dynamical tropopause DT (see text for details). Pure Tropospheric Ozone Column $(P T O C)$ is the difference between TOC and SIC.

such ozone thicknesses is to help, on the one hand, the satellite remote sensing and the radiative transfer communities, mostly interested by TOC and, on the other, the regional air quality community, mostly interested in the volume mixing ratio, which can easily be derived from $O L T$ (see Eq. (6) in the Appendix). Although the vertical resolution of MOZAIC raw data is as good as a few tens of metres, we chose to compute $O L T$ over a $150-\mathrm{m}$ vertical depth to avoid useless computations of associated $P V$ profiles at very high vertical resolution with the ECMWF analyses.

Stratospheric intrusions into the troposphere occur during tropopause folding in narrow regions near uppertropospheric fronts (Danielsen, 1968) and can be traced by characteristic features like high static stability, high ozone content, low water vapour content, and high potential vorticity. In the presence of a tropopause fold, e.g. when the 2 pvu contour folds below the dynamical tropopause level (see Fig. 2), ozone of stratospheric origin is included in the TOC as we have defined it. TOC may be dramatically increased with stratospheric-origin intrusions because ozone observations across tropopause folds often show high ozone concentrations. For instance, Danielsen et al. (1987) and Browell et al. (1987) reported mixing ratios of ozone in excess of $200 \mathrm{ppbv}$ in a 2.0-km-deep tropopause fold observed with airborne lidar and in situ measurements in the upper troposphere. The contribution of stratospheric-origin ozone to TOC assessed using Eq. (A6) (see Appendix) for a hypothetical tropopause fold of $1.5-\mathrm{km}$ depth with a $150-\mathrm{ppbv}$ homogeneous ozone mixing ratio at $400 \mathrm{hPa}$ and $-20^{\circ} \mathrm{C}$ is about $10 \mathrm{DU}$ (or equivalently $1 \mathrm{DU} / 150 \mathrm{~m}$ on the vertical), which may represent up to $50 \%$ (25\%) of the monthly-mean TOC observed at mid-latitudes during winter (summer) as described in following sections. Stratosphere-troposphere exchange (STE) may therefore be a more or less important contributors to the tropospheric ozone budget according to whether intrusions are deep, transient or shallow when they penetrate into the troposphere (Wernli and Bourqui, 2002; Stohl et al., 2003). The identification of the stratospheric origin of air parcels with thermodynamical parameters may be achieved through Lagrangian approaches (Wernli and Davies, 1997; Stohl, 2001). Here, the Lagrangian parameter used, the Reconstructed Potential Vorticity $(R P V)$, is the $P V$ value at the end of a 24-hour backward air parcel trajectory initialized at the location of the observation and computed with 6-hourly winds from ECMWF analyses. For backward trajectories the Lagrangian method uses a cubic polynomial interpolation of three-dimensional winds. A recent stratospheric origin $(\leq 24 \mathrm{~h})$ is allocated to an air parcel if three criteria are met: $R P V \geq 1.5 \mathrm{pvu}$, altitude $>2000 \mathrm{~m}$ and observed relative humidity $(R H)<50 \%$. The criterion on $R P V$ is a compromise. It has to be less than that in order to take into account non-conservation effects in trajectories and the numerical diffusion by the parent model. The magnitude of $R P V$ has to be large enough to avoid capturing troposphericorigin air parcels with $P V$ diabatically enhanced in a region of strong latent heat release. The second criterion on the altitude prevents capture of air parcels with a relatively large $P V$ enhanced by a thermal inversion at the top of the Boundary Layer. Finally, the dryness criterion on the relative humidity is to strengthen the characteristics of stratospheric-origin air. No criterion is imposed on the ozone observation as it will be used to test the confidence in the method. With this method and as illustrated in Fig. 2, we define two new quantities. The Stratospheric Intrusion Column (SIC) is the integrated ozone 
profile through layers that satisfy stratospheric-origin ozone criteria $(R P V>1.5 \mathrm{pvu}, z>2000 \mathrm{~m}, \mathrm{RH} \leq 50 \%)$ below the dynamical tropopause. The Pure Tropospheric Ozone Column $(P T O C)$ is the difference between TOC and SIC.

In order to illustrate the computation of TOC, SIC and PTOC quantities, four individual MOZAIC profiles over Frankfurt are illustrated in Fig. 3:

- The first vertical profile (Fig. 3a) presents typical signatures of the tropopause, like the change in the temperature lapse rate, the dryness, and the well defined vertical gradient of ozone mixing ratio. The dynamical tropopause $D T$ is given at $7850 \mathrm{~m}$ altitude with the $P V$ threshold which is correct with respect to the temperature lapse rate and acceptable with respect to the ozone mixing ratio as an universally accepted criterion on chemical tropopause is quite difficult to establish (Thouret et al., 1998a). In consequence, the rapid increase of the $O L T$ profile from 0.6 to $0.8 \mathrm{DU} / 150 \mathrm{~m}$ just below the tropopause is counted as a contribution to $T O C$, which is uncertain but has nevertheless a minor impact. TOC is about $21 \mathrm{DU}$ and there is no contribution of stratospheric origin in it as the $R P V$ profile never exceeds the 1.5 pvu threshold.

- The second vertical profile (Fig. 3b) also presents clear tropopause signatures in the observations, which is consistent with the dynamical tropopause given at $10028 \mathrm{~m}$. The RPV threshold method detects a typical stratospheric-origin layer in the mid troposphere between $5812 \mathrm{~m}$ and $6679 \mathrm{~m}$ where ozone is anticorrelated with the relative humidity, and the temperature lapse rate is decreasing. In this layer, the ozone mixing ratio is higher than $100 \mathrm{ppbv}$, or equivalently, $O L T$ is larger than $0.8 \mathrm{DU} / 150 \mathrm{~m}$. The contribution of SIC to TOC is $5.93 \mathrm{DU}$, about $18 \%$ of TOC.

- On the third vertical profile (Fig. 3c), the dynamical tropopause is defined and crossed at $9828 \mathrm{~m}$. Data show a characteristic tropopause fold at around $4700 \mathrm{~m}$ altitude, with a 90 ppbv ozone peak, $10 \%$ minimum relative humidity and maximum $O L T$ close to $0.8 \mathrm{DU} / 150 \mathrm{~m}$. The case was studied by Nédélec et al. (2003) in a validation paper for ozone and carbon monoxide measurements from the MOZAIC programme. However, this tropopause fold is not detected by the $R P V$ threshold method, and so does not contribute to SIC, though it does contribute to TOC. This shows that improvements of the Lagrangian approach would certainly be needed to capture all stratospheric intrusions. Below the tropopause there are some layers where $R P V$ exceeds its 1.5-pvu threshold, but these layers are considered to be of tropospheric origin because humidity is very high.

- In the last example (Fig. 3d), the dynamical tropopause is defined at $11000 \mathrm{~m}$ and is not crossed by the aircraft, which stops climbing at about $9 \mathrm{~km}$ altitude. The vertical profile of $O L T$ (in DU/150 m) has been filled up from $9128 \mathrm{~m}$ to the level of the dynamical tropopause with a method described in the next section. In the planetary boundary layer, ozone pollution is visible with a $80 \mathrm{ppbv}$ maximum at $1000 \mathrm{~m}, O L T$ values exceed $1.2 \mathrm{DU} / 150 \mathrm{~m}$ and strongly contribute to TOC, which is close to $40 \mathrm{DU}$.

To summarise, TOC values of the previous MOZAIC profiles are between 23 and 40 DU. The maximum $O L T$ contribution to TOC can be located in the boundary layer, the mid troposphere or the upper troposphere. A given ozone mixing ratio will obviously contribute more to TOC in the lower troposphere than at any other higher level in the troposphere, because of greater air density at lower altitudes (Eq. (A6) in the appendix).

\subsection{Missing data in vertical profiles}

Data may be missing from tropospheric profiles for two reasons. First, there are data gaps that are due to the operation of the MOZAIC ozone analyzer (internal calibration periods, resets, powercuts, etc.). Such data gaps take up one or several 150 -m deep layers with a frequency that does not exceed $5 \%$ of the data set used in this study. If data is missing for just one $O L T$ (i.e., a 150-m deep layer; see Fig. 2) in a profile, then the missing value is computed using a linear interpolation between data of the two nearest layers in the same profile. If data for more than one $O L T$ are missing (i.e. a gap exceeding $150-\mathrm{m}$ depth), each missing $O L T$ value is replaced by its seasonal climatological value computed using the MOZAIC dataset (see Sect. 4.1). Second, there are the MOZAIC profiles that do not reach the dynamical tropopause. Here, our strategy is to fill up the unexplored atmospheric layers as high as possible by replacing missing $O L T$ values with their corresponding seasonal climatological values. If the dynamical tropopause for a given flight is situated above the top of the seasonal climatological profile (about $12 \mathrm{~km}$ altitude in practice for MOZAIC aircraft), the profile is filled up to the latter level. We decided not to fill up the unexplored remainder. The contribution to TOC of the unexplored remainder of the profile is all the more important since the tropopause is high. Nevertheless there is a balancing effect due to the dependence of $O L T$ on pressure. The impacts of the filling-up process and unexplored remainders of profiles are evaluated and discussed below.

On an annual-mean basis, the dynamical tropopause is crossed for $44.4 \%$ of the MOZAIC vertical profiles in Frankfurt, $39.5 \%$ in Paris, $33.5 \%$ in New York and $19.0 \%$ over Japan (see column P1 in Table 2). Filling-up vertical profiles with seasonal climatological $O L T$ values when the tropopause of the day is higher than the top of the aircraft profile occurs for $47.6 \%$ of the profiles in Frankfurt, for $50.2 \%$ in Paris, for $38.2 \%$ in New York, and for $25.3 \%$ over 

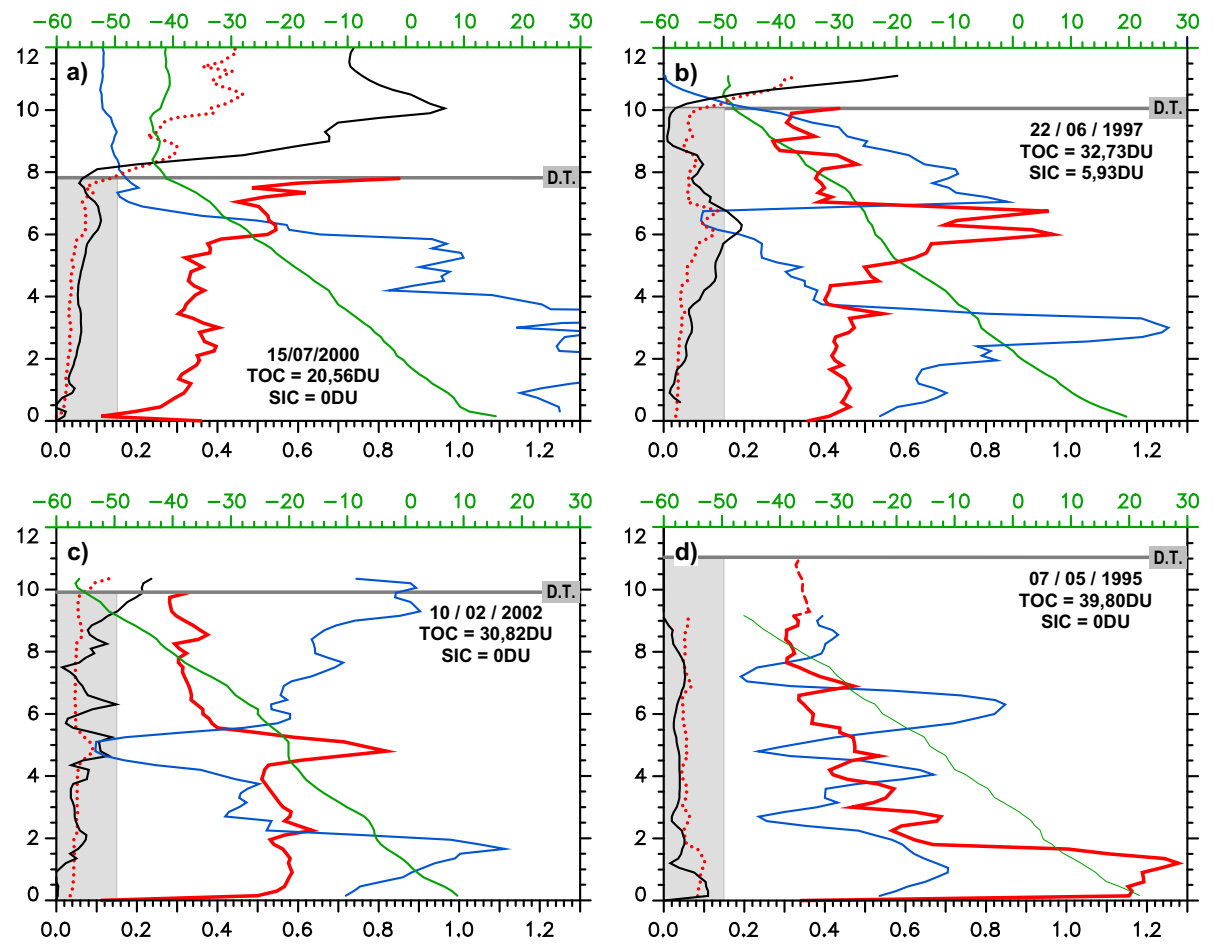

Fig. 3. Individual MOZAIC vertical profiles (in km) over Frankfurt. Lower horizontal scale is for the ozone mixing ratio [in ppmv - red dotted line], OLT [in DU - red solid line or red dashed line if the profile has been filled up to the altitude of the dynamical tropopause using the monthly-average $O L T$ profile], relative humidity $[\times 100 \%$ - blue line $]$ and reconstructed potential vorticity $[\times 10 \mathrm{pvu}-$ black line $]$. The upper horizontal green scale is temperature $\left[{ }^{\circ} \mathrm{C}\right.$ - green line]. TOC is computed over a column from the ground to the $D T$ [dark grey horizontal line]. A tropospheric layer contributes to $S I C$ if three criteria are met: altitude between $2 \mathrm{~km}$ and the $D T$, relative humidity lower than $50 \%$ and reconstructed potential vorticity exceeding 1.5 pvu (i.e. if the black line exits on the right of the shaded grey pattern).

Table 2. Statistics on MOZAIC vertical profiles available between August 1994 and February 2002 at the four stations: P is the total number of available vertical profiles; P1 is the number of vertical profiles for which aircraft have crossed the dynamical tropopause; P2 is the number of vertical profiles that have been filled up to the dynamical tropopause with the corresponding part of the seasonal-average tropospheric OLT profile (see Fig. 6); P3 is the number of vertical profiles unavailable for the study because PV data are missing; P4 is the number of vertical profiles for which the aircraft did not cross the tropopause and for which the tropopause of the day is above the highest altitude level defined by the seasonal-average tropospheric $O L T$ profile. Values in brackets are corresponding percentages.

\begin{tabular}{lccccc}
\hline Station & P & P1 & P2 & P3 & P4 \\
\hline Frankfurt & 6338 & $2813(44.4)$ & $3015(47.6)$ & $100(1.6)$ & $410(6.5)$ \\
Paris & 3308 & $1307(39.5)$ & $1662(50.2)$ & $45(1.4)$ & $294(8.9)$ \\
New York & 2631 & $881(33.5)$ & $1006(38.2)$ & $25(1.0)$ & $719(27.3)$ \\
Japan & 1899 & $360(19.0)$ & $481(25.3)$ & $23(1.2)$ & $1035(54.5)$ \\
\hline
\end{tabular}

Japan (column P2). Some vertical profiles are still uncompleted after this step because the $P V$ profiles are not available in the data base; this occurs for less than $2 \%$ of the profiles whatever the site (column P3). Finally, there are other uncompleted profiles because the tropopause of the day is higher than the maximum altitude of the seasonal climatological profile. The proportion of profiles affected ranges from $6.5 \%$ over Frankfurt to $54.5 \%$ over Japan (column P4). The statistics of the Japanese profiles are very different from those for the other cities because, in summer, the tropopause over Japan is very frequently much higher due to the position of Japan, just south of the summertime subtropical jet stream. We chose to discard only P3 profiles from this study. Discarding all incomplete profiles (P2 and P4 columns) would bias the study towards systematically lower tropopause situations and eliminate about $80 \%$ of the Japanese profiles for the mid troposphere and the boundary layer study. Keeping these profiles avoids the aforementioned bias. However the 

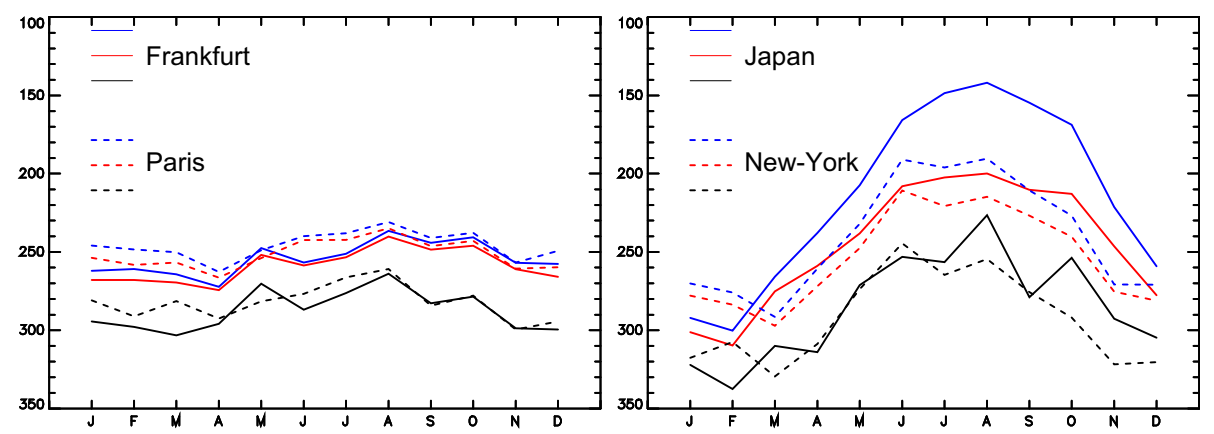

Fig. 4. Monthly-mean pressures of the dynamical tropopause $D T$ (in hPa) deduced with a $P V$ threshold (2 pvu) on ECMWF analyses at the four stations: blue lines show DT sampled at the frequency of MOZAIC aircraft, black lines show DT sampled at the frequency of MOZAIC profiles that cross the tropopause (column P1 in Table 2), and red lines show DT with the sampling frequency of MOZAIC profiles that cross the tropopause or that have been filled up to it (columns P1, P2 and P4 in Table 2, see text for details).

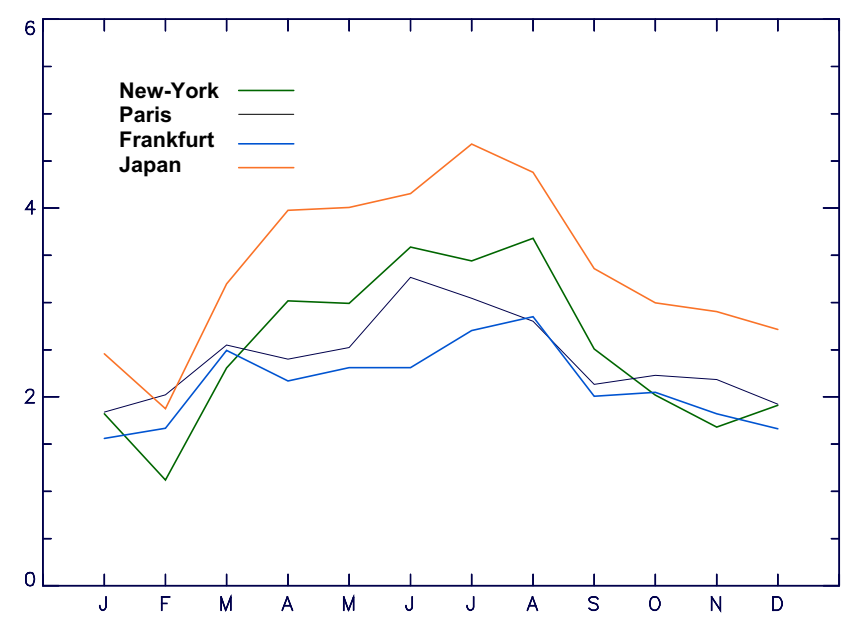

Fig. 5. Monthly-mean contribution to the Tropospheric Ozone Column (DU) by the filling-up process applied on MOZAIC vertical profiles in columns $\mathrm{P} 2$ and $\mathrm{P} 4$ of Table 2.

filling-up process weights the assessment of the short-term trend of TOC with the contribution of a fixed seasonal value, and there is an underestimation of TOC for $\mathrm{P} 4$ profiles. These effects, which may become important in New York and Japan during summertime when the tropopause is the highest, are assessed below. Note that a further extension of the present work would be to consider known ozone climatologies (e.g., Logan, 1999) in order to fill in any missing vertical ozone data over MOZAIC sites.

Monthly mean pressure of the dynamical tropopause for the four MOZAIC sites is shown on Fig. 4. Blue lines are results in pressure of the tropopause detection method with the $P V$ threshold on ECMWF analyses at the sampling frequency of MOZAIC flights (Column P in Table 2). A marked low (high) tropopause is visible in winter (summer) over New York and over Japan, whereas the seasonal variations of tropopause pressure over Frankfurt and Paris are rather small. Differences are mainly due to the positions of the sites with respect to main storm-tracks: in the entrance region of Atlantic (Pacific) storm-tracks for New York (Japan), and in the exit region of the Atlantic storm-tracks for Frankfurt and Paris. Black lines show the monthly mean pressure of the dynamical tropopause when it is crossed by MOZAIC aircraft (Column P1 in Table 2), and red lines show monthly mean pressure after the filling-up process on vertical profiles (Columns P1 plus P3 in Table 2). Therefore, for a given station, the difference between black and red lines is a measure of the efficiency of the method used to fill up the vertical profiles (the more widely separated the lines, the more effective the method), and the difference between red and blue lines is a measure of the depth of the unexplored remainders below the tropopause (the more widely separated the lines, the thicker the layer). Over Frankfurt, and Paris, the mean depth of unexplored remainders is very small $(\simeq 10 \mathrm{hPa})$ and is constant throughout the year. Over New York, it is quite thin in winter and spring but increases to about $20-30 \mathrm{hPa}$ from June to September. Over Japan, the maximum depth of unexplored remainders is about $60 \mathrm{hPa}$ during summer. The summertime TOC over New York and over Japan analyzed in Sect. 4 are therefore underestimated because of the non-negligible depth of unexplored remainders below the tropopause. Based on a mean value for $O L T$ of $0.3 \mathrm{DU} / 150 \mathrm{~m}$ (see Sect. 4), the maximum summertime losses in unexplored remainders are estimated to be about 0.3 DU over Frankfurt, 3 DU over New York and 5 DU over Japan. The monthlymean contribution to TOC by the filling-up process is shown on Fig. 5. This contribution corresponds to the integrated ozone profile through the part of the upper troposphere which is bordered by the red and blue lines of Fig. 4 and that has been filled up with the corresponding part of the seasonal climatological profile. During summer it ranges from 2.8 DU at Frankfurt to 4.7 DU over Japan, while this contribution is about to $2 \mathrm{DU}$ for all sites during winter. It is assessed to be about $10 \%$ of TOC whatever the season and the site. It is clear that the filling-up process improves the quantitative assessment of TOC. However, it also has an impact on the 
investigation of short-term trends by introducing a component that is time-independent in the dataset.

\section{Climatological analysis}

\subsection{Vertical profiles}

Seasonal climatological vertical profiles of $O L T$ are plotted on Fig. 6. The vertical gradient of $O L T$ is positive in the boundary layer whatever the season and the site, and becomes negative in the free troposphere. Then, a difference can be seen according to whether the seasonal-mean is computed with all profiles (thin lines) or with sections of the profiles below the dynamical tropopause (thick lines).

With all profiles, the large stratospheric ozone concentrations make the vertical gradient of $O L T$ return to positive values in the upper part of the profile (Fig. 6, thin lines). The range of altitudes where the vertical gradient of $O L T$ changes its sign is close to the seasonal-mean tropopause, i.e. between 8 and $10 \mathrm{~km}$ on every station and for every season except i) over New York in winter and spring, and Japan in winter, where the changes occur slightly below $8 \mathrm{~km}$, ii) over New York in summer, and Japan in summer and autumn, where the change occurs above $10 \mathrm{~km}$. A noticeable feature is that $O L T$, in this region of $8-10 \mathrm{~km}$ altitude, has values smaller than in the planetary boundary layer. In the context of the links between ozone trends in the UTLS region and radiative forcing, the latter feature is important because the contribution of a perturbation on the ozone vertical profile to the change in surface temperature is maximum in the UTLS region (Forster and Shine, 1997). Because the ceiling altitudes of MOZAIC aircraft are nearly always below the tropopause over Japan in summer and autumn, the positive vertical gradient of $O L T$ in the lower stratosphere is not defined on the seasonal time scale. In the lower stratosphere, maximum $O L T$ values are observed during spring and range from 0.9 DU/150 m over Japan to $1.4 \mathrm{DU} / 150 \mathrm{~m}$ in Frankfurt. Minimum $O L T$ values of about $0.5 \mathrm{DU} / 150 \mathrm{~m}$ are observed during autumn. Seasonal-mean values of $M O C$, i.e. vertical integrals of thin lines, range from 31 to $50 \mathrm{DU}$ and go through a maximum in spring at each MOZAIC station.

With all sections of the profiles below the dynamical tropopause (Fig. 6, thick lines), seasonal climatological profiles are such that the negative vertical gradient of $O L T$ extends up to the MOZAIC aircraft ceiling in the uppermost troposphere. Seasonal-mean values of TOC, i.e. vertical integrals of thick lines shown in Fig. 6, range from 26 to 39 DU and go through a maximum in summer at each MOZAIC station except Japan. Very well defined maxima of $O L T$ are observed in the planetary boundary layer. New York has the highest ozone-polluted boundary layer in summer with a maximum of $0.75 \mathrm{DU} / 150 \mathrm{~m}$. An exception occurs for Japan where maritime-origin ozone-poor air masses of the summermonsoon season are associated with low $O L T$ values up to
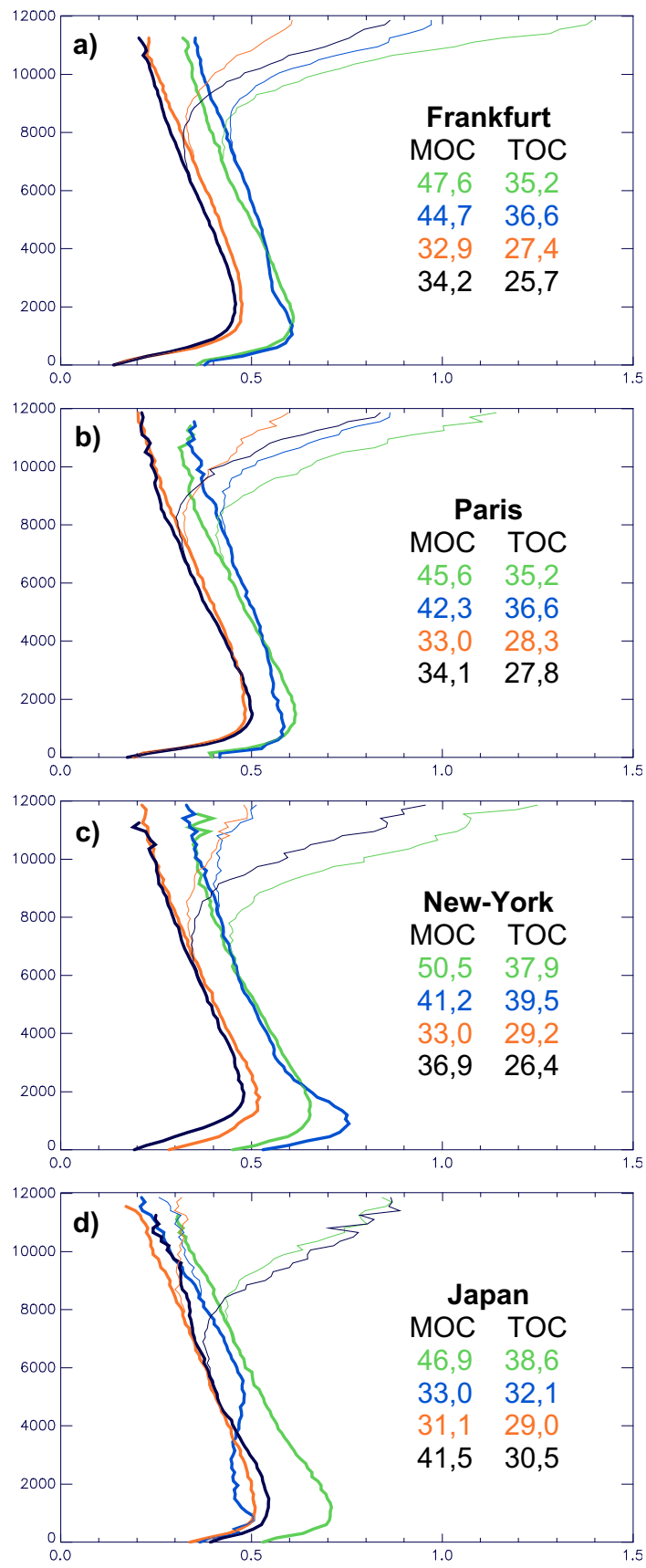

Fig. 6. Seasonal climatological vertical profiles (in $\mathrm{m}$ ) of Ozone Layer Thickness (OLT, in DU/150 m) for Frankfurt, Paris, New York and Japan. (Thin lines): no distinction is made with regard to the altitude of the dynamical tropopause. Vertical integrals are the seasonal climatological MOC (DU). (Thick lines): made with sections of the profiles below the dynamical tropopause. Vertical integrals are the seasonal climatological TOC (DU). Colors: green for spring, blue for summer, orange for autumn and black for winter.

$5 \mathrm{~km}$ altitude. Finally, an interesting feature of $O L T$ tropospheric seasonal-mean profiles (thick lines) is their separation into two classes, i.e. spring-summer and autumn-winter 

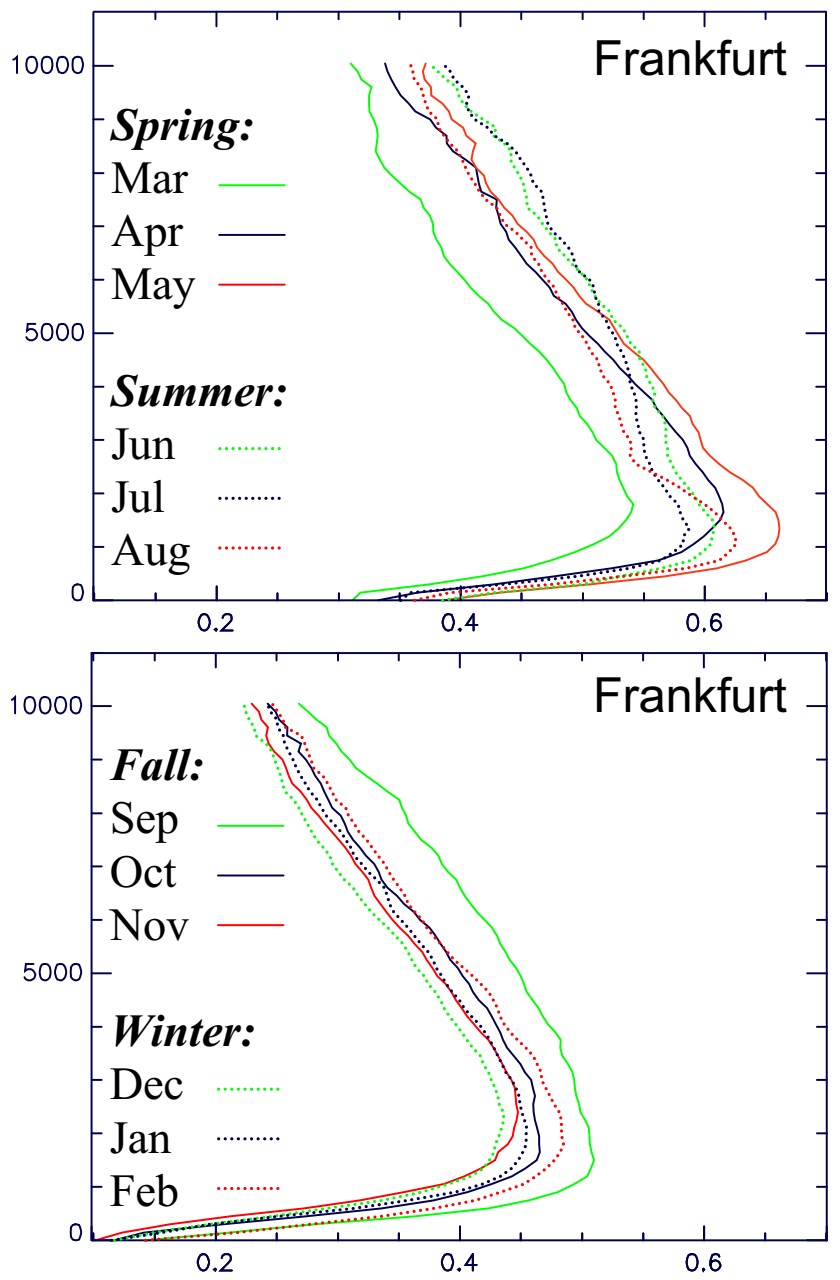

Fig. 7. Monthly-mean tropospheric profiles (in $\mathrm{m}$ ) of $O L T$ (DU/150 m) over Frankfurt.

profiles. This classification also shows up on a monthly basis as seen, for instance, for Frankfurt (see Fig. 7). March and September appear to be transitional months between the two classes. Synthetic ozone profiles can be easily built from these averaged data for initialization purposes in chemistry transport models and retrieval techniques for satellite products.

\subsection{Seasonal cycle}

The seasonal cycle of monthly-mean TOC over MOZAIC sites is presented in Fig. 8a. Paris and Frankfurt show a very similar seasonal cycle with a broad maximum of about $34 \mathrm{DU}$ from April to August and a minimum of about 22 DU in December. The seasonal cycle over New York is similar to European cycles except for its larger range with a broad spring-summer maximum that peaks at $39 \mathrm{DU}$ in June. It is interesting to note the rapid springtime increase at the three stations and then a dropping off during the late summer. The rapid springtime increase is consistent with photochemical ozone production after ozone precursors have accumulated in the troposphere in winter and when insolation increases. The contribution of stratosphere-troposphere exchange to this cycle is discussed in the following section. Over Japan, the seasonal cycle is quite different. The earlier springtime increase is consistent with a latitudinal effect (earlier springtime sun) as Japanese stations are the southernmost stations considered here. Winter and spring values are 2-3 DU larger than those at other sites. The cycle goes through a $38 \mathrm{DU}$ maximum in May, then abruptly falls to $28 \mathrm{DU}$ during the summermonsoon season (July) and slowly decreases to 25 DU in December.

The four $U T$ seasonal cycles (Fig. 8b) are all in phase; they display a maximum in late spring (except Frankfurt) and a secondary maximum (except Paris) in late summer. The amplitude is larger for New York and for Japan, in agreement with the summertime elevated tropopause there. The phasing of all four $U T$ cycles suggests that the summer monsoon over Japan does not influence the upper-tropospheric ozone budget.

Mid-tropospheric contributions to TOC (Fig. 8c) are predominant $(\approx 60 \%$ of TOC). Interestingly, the two European seasonal cycles are almost identical to the one for New York. The peak is in May-June and the minimum in December. It is likely that the similarity of these three mid-tropospheric cycles has something to do with the homogenization of the distributions of trace gases that have a sufficient lifetime (a few weeks), like ozone, by the large-scale circulation. The latitudinal and the summer-monsoon effects that influence the Japanese seasonal cycle are clearly visible in the mid troposphere.

Boundary layer contributions (Fig. 8d) represent roughly a $25 \%$ contribution to TOC. These contributions are $10 \%$ higher in New York compared to Frankfurt and Paris during spring and summer, and are 10\% higher in Japan compared to New York, Frankfurt and Paris during autumn and early spring. Local and remote anthropogenic emissions as well as biomass burning over upstream regions of Asia may be responsible for larger low- and mid-tropospheric contributions to TOC over Japan throughout the year except during the summer-monsoon season.

It is possible to make a direct comparison of our results with those of Creilson et al. (2003) who used a technique based on coincident observations of the Total Ozone Mapping Spectrometer (TOMS) and stratospheric ozone profiles from the Solar Backscattered Ultraviolet (SBUV) instruments to retrieve tropospheric ozone residuals (TOR). Their Fig. 5 shows the monthly climatological tropospheric ozone residuals for two regions centred over Washington D.C. (USA) and over Bordeaux (France) together with a comparison, for validation purposes, with tropospheric ozone columns integrated with ozonesonde data at Wallops Island (USA) and at Hohenpeissenberg (Germany). Comparisons with our seasonal cycles for TOC in Frankfurt and in New York (Fig. 8a) are near-perfect. Summertime differences 
come from the missing contribution in the upper troposphere when tropopause-crossings by MOZAIC aircraft diminish. The summertime underestimations of TOC are less than 1 DU in Frankfurt and 5 DU in New York.

\subsection{Stratospheric Intrusion Column}

The purpose here is to test the validity of the Lagrangian approach used to detect stratospheric-origin air parcels (see Sect. 3.1), and to evaluate the contribution of the stratospheric-origin ozone, i.e. the Stratospheric Intrusion Column SIC, to the Tropospheric Ozone Column TOC. Over Japan, there is a large seasonal variation in the frequency of flights affected by STE (i.e., SIC $>0$ ), from $69 \%$ in January down to $15 \%$ in August (not shown). Such a large frequency range may be explained by favourable wintertime dynamics for STE in the region of the subtropical jet (Sprenger et al., 2003) and by unfavourable summertime monsoon dynamics. Over Paris, Frankfurt and New York and whatever the season, about one third of the vertical profiles contain signatures of stratosphere-troposphere exchange (not shown). The quasiabsence of seasonal variation of STE frequency over New York, Paris and Frankfurt stations is an indication that the criterion used here to compute SIC accumulates transient and deep events. According to Lagrangian studies exploring the sensitivity of the residence time criterion of air parcels (e.g. Wernli and Bourqui, 2002; James et al., 2003), transient and deep events respectively lead to weak and strong seasonal cycles of the zonally integrated cross-tropopause mass-fluxes. Tropospheric depths of tropopause folds are quite variable. For instance, Danielsen et al. (1987) observed a depth that decreased from 2 to $0.6 \mathrm{~km}$ as the folds descended from 6 to $2 \mathrm{~km}$ altitude. In accordance with the latter study, the average depth of stratospheric-origin layers assessed here is $750 \pm 150 \mathrm{~m}$. Monthly-mean concentrations of ozone observed in stratospheric intrusions are shown on Fig. 9a for the upper troposphere and the mid troposphere. Mean concentrations in the upper troposphere are higher than in the mid troposphere for every month and every station (except for July over New York, October over Paris and March over Japan, where opposite differences not exceeding $15 \mathrm{ppbv}$ come from irregularities in the sampling frequency). During the monsoon season (August) over Japan, there is no stratospheric influence detected in the mid troposphere. An upper tropospheric maximum forms in May-June, with about 150 ppbv over New York and Japan, and 110 ppbv over Paris and Frankfurt. An upper tropospheric minimum ranges from 70 to $90 \mathrm{ppbv}$ during winter over the four stations. Some observed values exceed 250-300 ppbv which indubitably indicates stratospheric origin. For ozone layer thickness associated with stratospheric-origin air, Fig. $9 \mathrm{~b}$ shows the same general behaviour as for concentrations, except that this time mid-tropospheric values are always slightly larger than upper-tropospheric ones (except Japan in July) in agreement with the difference of air density. Note that springtime $O L T$
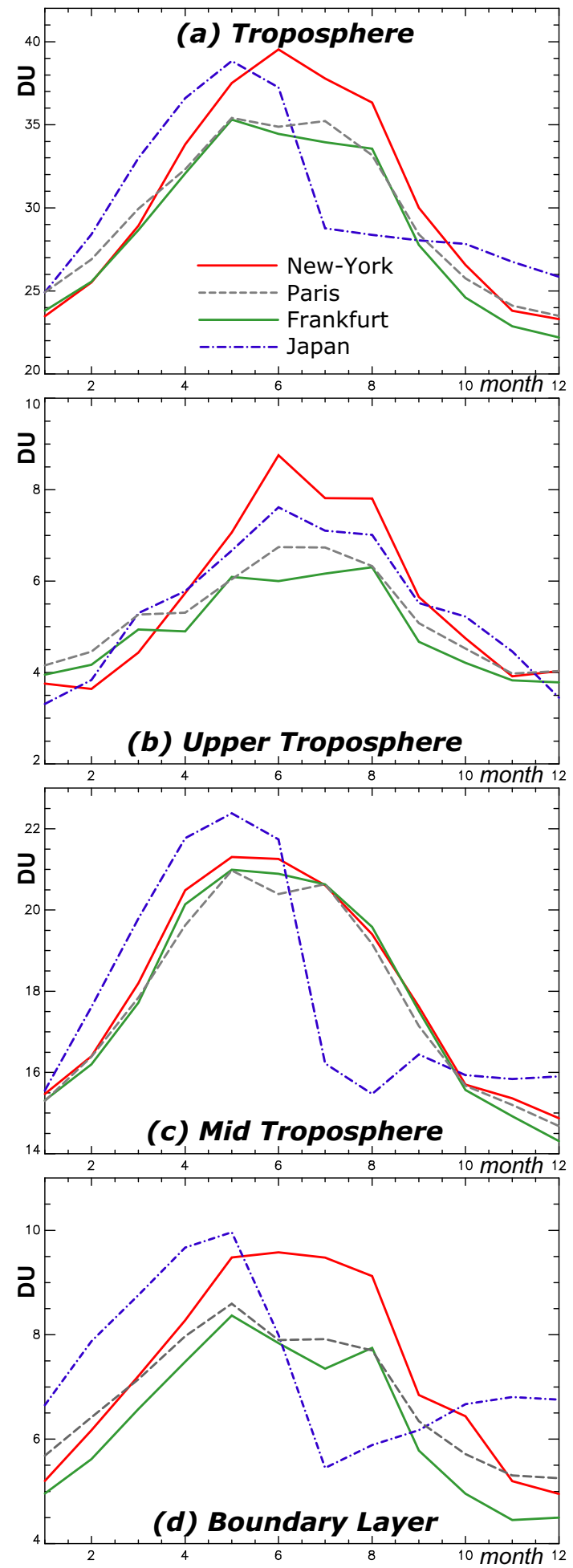

Fig. 8. Monthly-mean TOC seasonal cycle: (a) Total tropospheric contribution, (b) Upper-Tropospheric contribution, (c) MidTropospheric contribution, (d) Boundary Layer contribution. New York (red line), Paris (dashed black line), Frankfurt (green line) and Japan (dash-dotted blue line). 

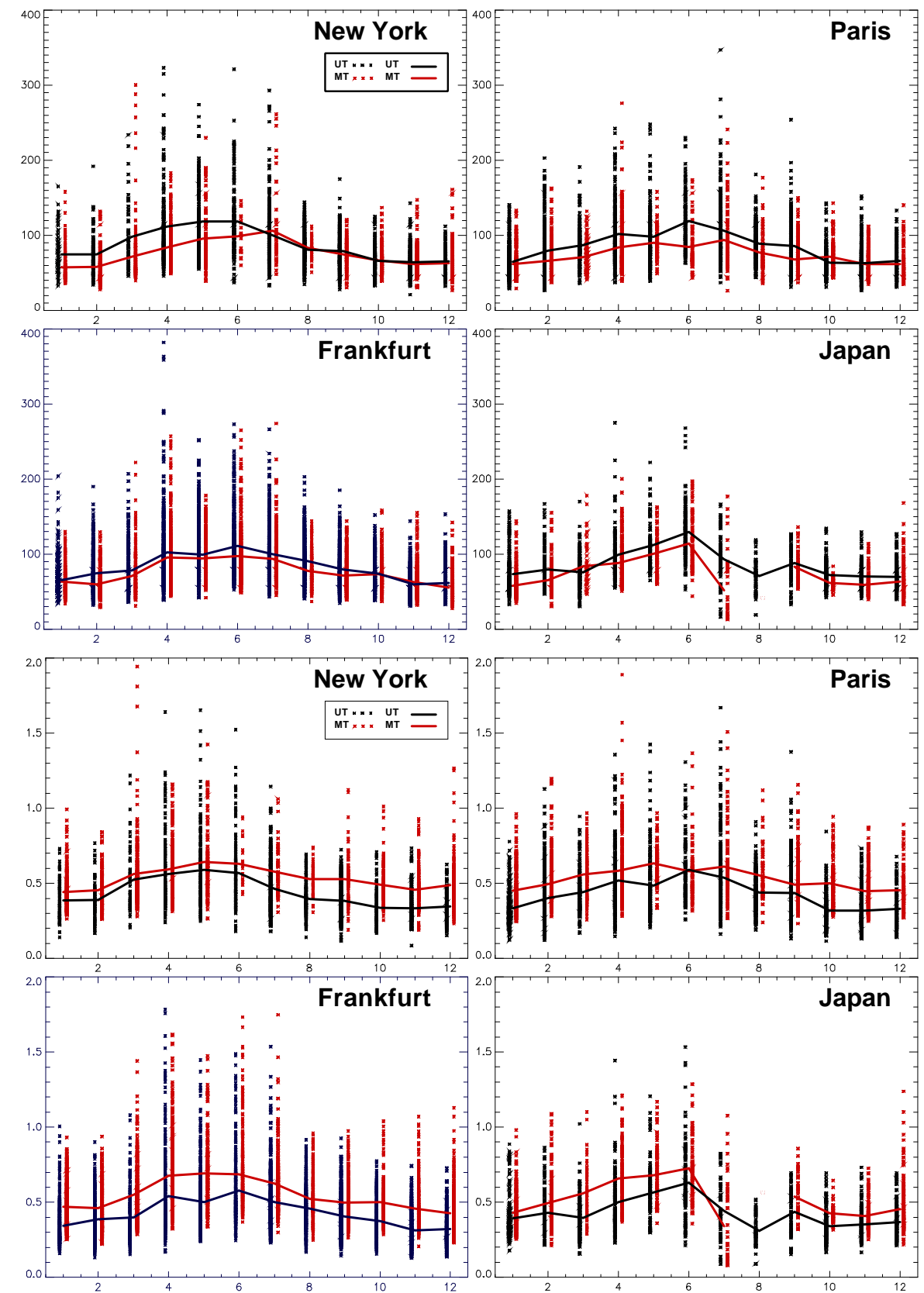

Fig. 9. (Top) Monthly-mean ozone concentration (ppbv) of 150 m-deep layers affected by stratosphere-troposphere exchange for the mid troposphere (red line) and for the upper troposphere (black line) over the four MOZAIC stations. (Bottom) Same as the top panel but for the ozone layer thickness (DU/150 m). In both panels the red (black) points correspond to individual observations in the mid troposphere (upper troposphere).

affected by stratospheric intrusions are about $0.6 \mathrm{DU} / 150 \mathrm{~m}$, which is close to the maximum of mean $O L T$ values observed in the polluted planetary boundary layer (see Fig. 6). If isolated maximum values are considered, both in mid- and in upper troposphere, they exceed $1.0 \mathrm{DU} / 150 \mathrm{~m}$ which is comparable to lower-stratospheric values.
Finally, Fig. 10 shows the monthly-mean SIC over the four stations. The seasonal cycle exhibits a springtime maximum of about $3 \mathrm{DU}$ and a minimum in autumn of about 2 DU, which roughly corresponds to $10 \%$ of TOC throughout the year. This figure of $10 \%$ is not directly comparable to model-derived figures. James et al. (2003) considered, in a Lagrangian study, that as much as $95 \%$ of the mass 
of the troposphere at any one time has been in the stratosphere within the preceding year. Roelofs and Lelieveld's (1997) model-derived figure of $40 \%$ pertains to the total contribution of ozone of stratospheric origin to the tropospheric ozone, whereas our estimate only includes recently added stratospheric air that has not had a chance to mix and be diluted by tropospheric air. Taking into account that several factors reduce the capture of stratospheric intrusions in our Lagrangian method (see Sects. 3.1 and 3.2), this is a strong result that confirms that the important role of stratospheretroposphere exchange in the tropospheric ozone budget can be further investigated with the MOZAIC dataset. Our results lay the foundations for further observation-based studies where improvements in the retrieval of SIC from the combination of MOZAIC data and a Lagrangian approach may include i) the computation of longer backward trajectories ( $>5$ days) to exploit the sensitivity to the residence time criterion to distinguish between transient and deep exchanges, ii) advection with 3-hourly wind fields (analysis alternating with 3-hour forecasts) to reduce interpolation errors due to the linear assumption on temporal changes, iii) the use of ERA40 re-analyses at ECMWF, which provide better quality fields than operational analyses in the 1990s at the beginning of MOZAIC and allow inter-annual variability in stratosphere-troposphere exchange to be inferred, iv) the comparison with a particle dispersion model (Stohl et al., 2000) where effects of turbulent mixing and deep convection are parameterized, v) the use of MOZAIC raw data (better vertical resolution with $4 \mathrm{~s}$ time resolution measurements, $\simeq 20-30 \mathrm{~m}$ vertical resolution), vi) other MOZAIC stations to complete the northern mid-latitudes study (Washington D.C., Chicago, Vienna, ...), vii) further verification with the MOZAIC CO measurements. However, beyond the rough assessment of SIC, we do not think that the precision of the present results allows inter-annual variability and short-term trends of TOC and PTOC to be investigated separately. In consequence, the following section concentrates on the shortterm trends and inter-annual variability of $T O C$.

\section{Short-term trends and interannual variability}

The present MOZAIC 7-year dataset allows a limited investigation of the inter-annual variability of the tropospheric ozone column and an assessment of the short-term trends. First, time series of monthly-mean TOC are considered in Sect. 5.1. Then, in Sect. 5.2, the inter-annual variability of TOC in association with positive and negative phases of the North Atlantic Oscillation is discussed.

\subsection{Short-term trends}

The time series of the monthly mean TOC from August 1994 to February 2002 at the four MOZAIC sites are shown on Fig. 11. Seasonal cycles go through a minimum in winter

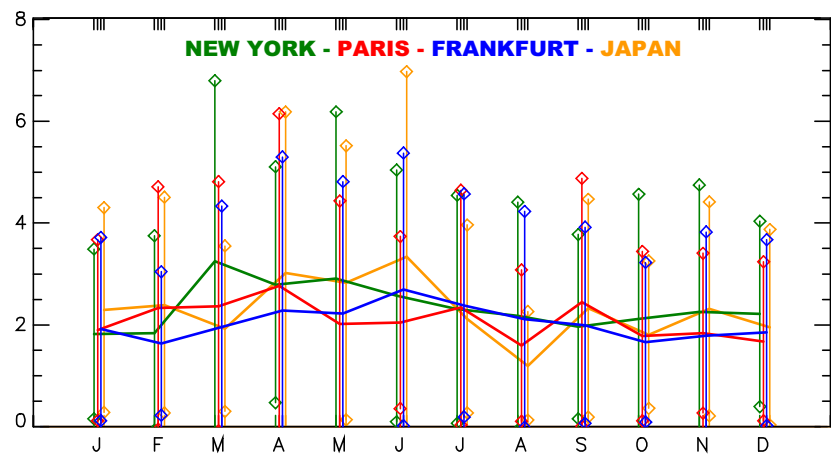

Fig. 10. Monthly-mean values of the Stratospheric Intrusion Column (SIC in DU), i.e. the integrated ozone profile through tropospheric layers that meet stratospheric-origin criteria. Vertical bars represent the standard deviations (DU). Colour code: blue for Frankfurt, red for Paris, green for New York, and orange for Japan.

and a maximum in summer, except for Japan where the maximum occurs during the spring because of the arrival of the monsoon in summer. The New York and Japan stations have the largest amplitude, roughly from $20 \mathrm{DU}$ to $44 \mathrm{DU}$. The Paris and Frankfurt stations have a lower amplitude, roughly from $20 \mathrm{DU}$ to $36 \mathrm{DU}$, and quite similar time series (except for differences due to better sampling over Frankfurt). Some noticeable and common features are i) high TOC values in summer 1998 over New York, Paris and Frankfurt, ii) high TOC values in summer 1999 over New York and Japan, iii) highest wintertime TOC in 1999 over all four stations, ranging from 24 to $26 \mathrm{DU}$, iv) continuous increase of wintertime TOC from 1996 to 1999 at New York, Paris and Frankfurt. Visual inspection of seasonal cycles in Fig. 11 gives the impression of a positive trend. This was confirmed by a statistical linear trend analysis over the 1995-2001 period, which shows a linear increase ranging from 0.7\%/year in Frankfurt to $1.1 \% / y e a r$ in New York. Note that incomplete seasonal cycles of 1994 and 2002 were discarded. The short-term trend over Paris (1.6\%/year) is derived over the 1995-1999 period as important data gaps in 2000 and 2001 prevent complete assessment of the seasonal cycle for these years.

Yearly seasonal mean TOC from 1994 to 2001 at the four MOZAIC sites are shown on Fig. 12. The separation into two classes, i.e. spring-summer and autumn-winter, already discussed for seasonal-mean vertical profiles (see Fig. 6), is reproduced here. Excluding Japan, New York (Paris) exhibits the largest (lowest) seasonal amplitude, about 13.8 DU (9.0 DU) from the summertime mean of $37.8 \mathrm{DU}$ (34.3 DU) to the wintertime mean of 24.0 DU (25.3 DU). Frankfurt and New York have the lowest wintertime mean of about 24.0 DU. Wintertime trends are positive and stronger than in the other seasons, about 2\%/year over New York, Paris and Frankfurt, and 1\%/year over Japan. Then, in descending order, come positive trends in spring and autumn and nearly non-existent summertime trends at the four stations. In 


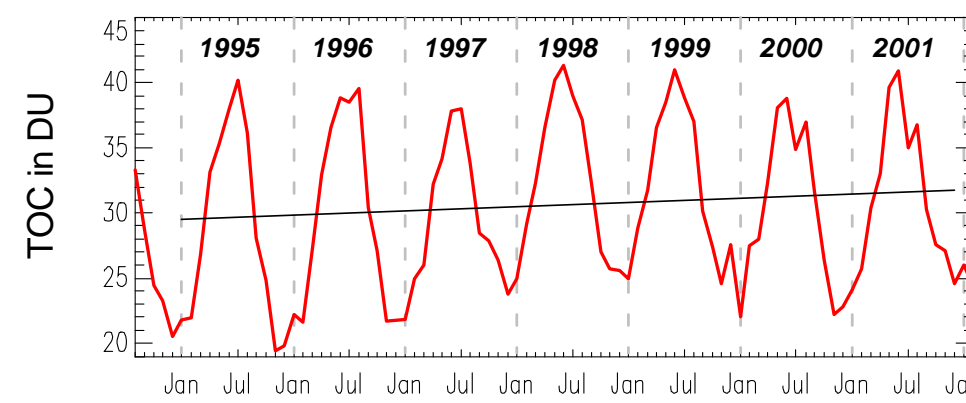

\section{New York \\ TOC $=30.3 \mathrm{DU}$ \\ $+1.1 \% /$ year}

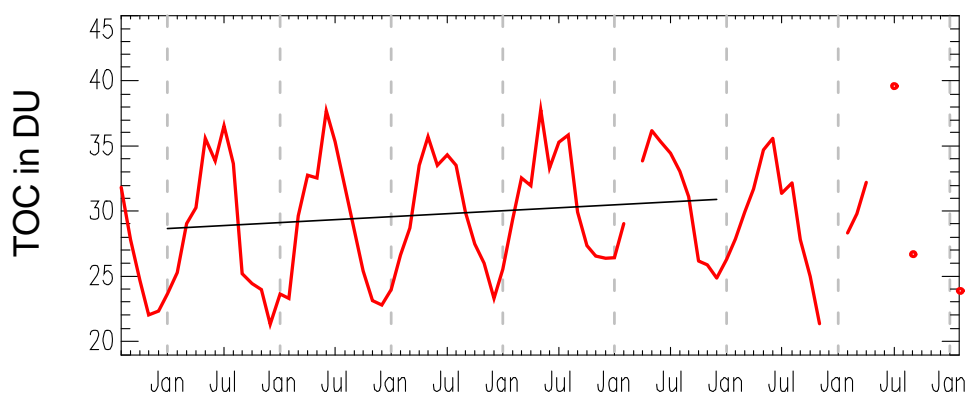

\section{Paris}

TOC $=29.7$ DU

$+1.6 \% /$ year

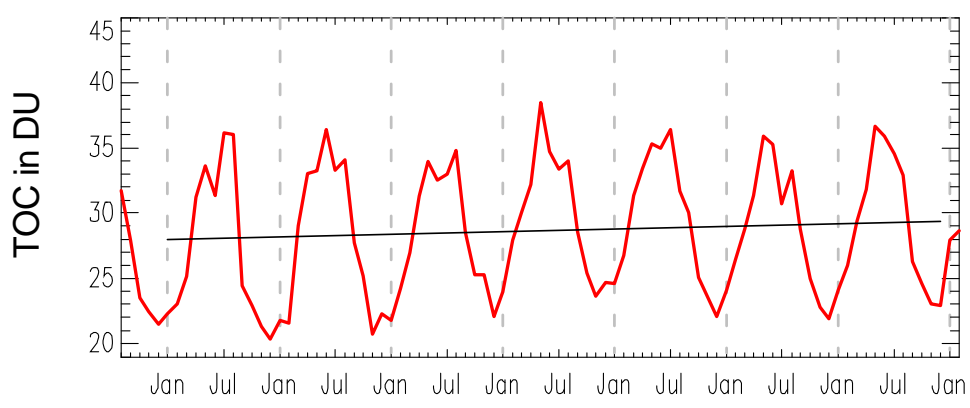

Frankfurt

TOC $=28.5 \mathrm{DU}$

$+0.7 \% /$ year
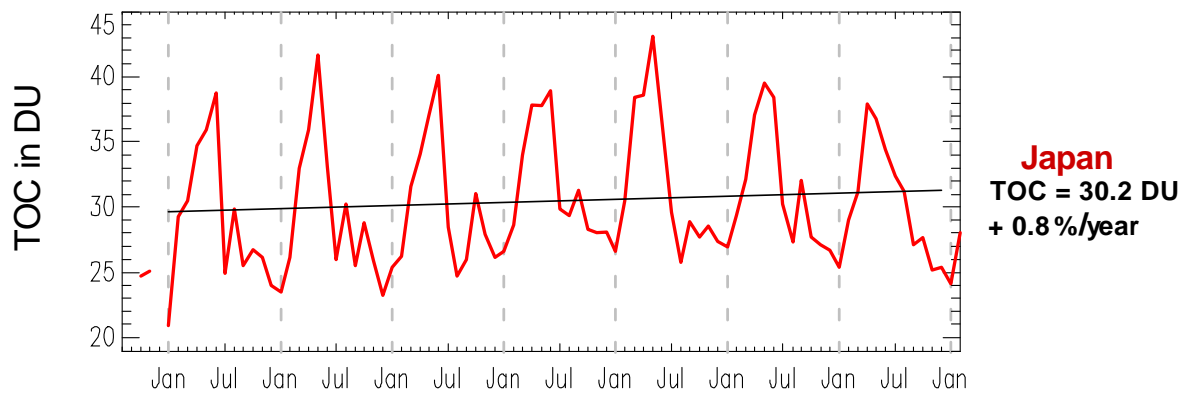

$+0.8 \% /$ year

Fig. 11. Time series of monthly mean Tropospheric Ozone Column TOC (DU, red solid lines) from August 1994 to February 2002 for the 4 MOZAIC stations. Indications on the right summarize the annual-mean TOC (DU) and short-term trends (\%/year) over the 1995-2001 period, or over the reduced 1995-1999 period for Paris.

relation to the linear increase, a wintertime bump or anomaly clearly appears in 1997 and 1998 at all four stations. Such an anomaly is more or less well defined from autumn 1997 to summer 1999 at all stations.

Table 3 sums up the annual-mean and seasonal-mean of TOC (DU) and the related trends (\%/year). It also details the contribution to TOC of the boundary layer, the mid troposphere and the upper troposphere. Noticeable wintertime features in New York, Paris and Frankfurt are the strong trends exceeding 3\%/year in the boundary layer and $1.7 \%$ year in the mid troposphere. There are strong upper-tropospheric wintertime trends (exceeding 1.7\%/year) at all stations except New York, where the trend is negative $(-0.7 \%$ /year). Summertime trends are generally close to zero whatever the part of the troposphere or the station, except over New York where the negative trend in the boundary layer is compensated by a positive one in the mid troposphere. Finally, it can be seen that, whatever the station and the season, midtropospheric trends are always positive. 

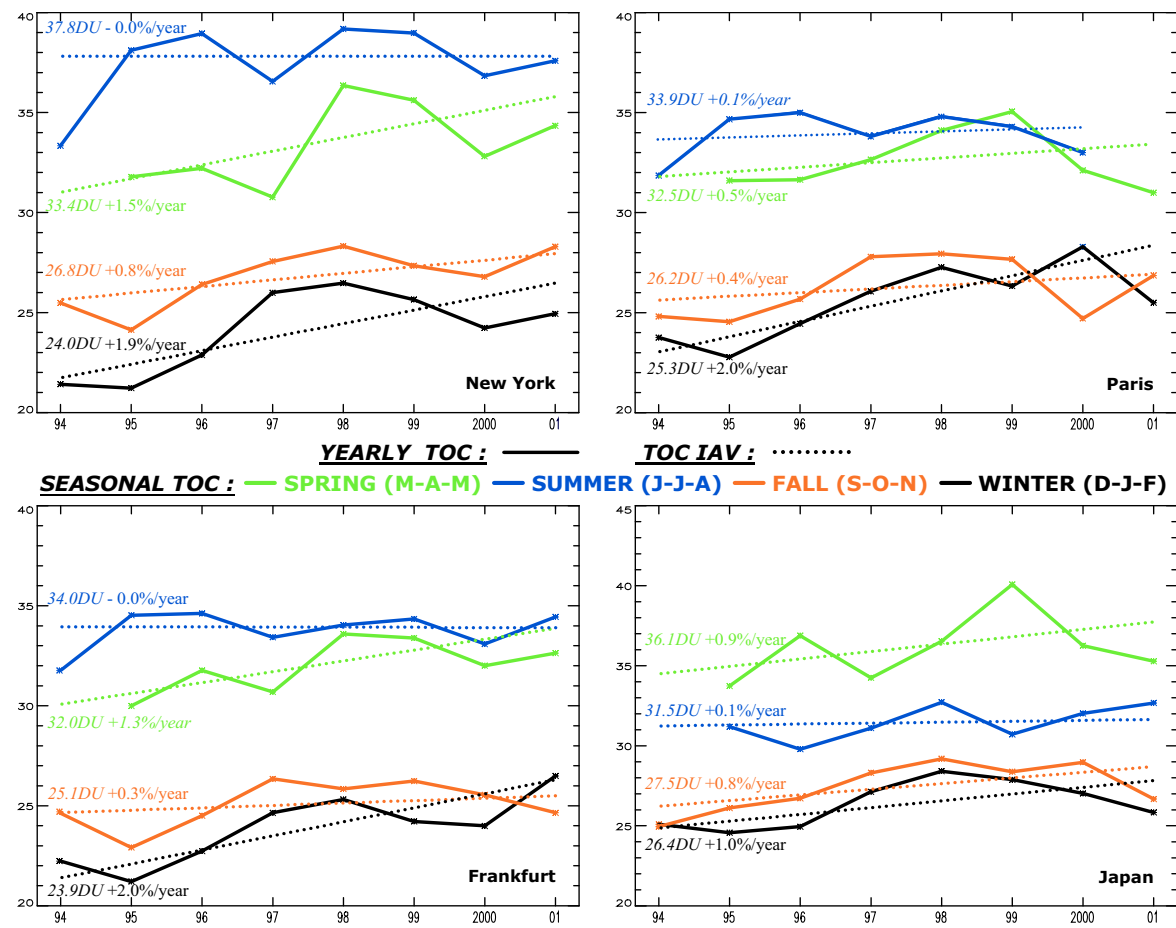

Fig. 12. Yearly seasonal-means for Tropospheric Ozone Column (DU) from 1994 to 2001 for the 4 MOZAIC stations (solid lines, green for spring, blue for summer, orange for autumn, black for winter). Dotted lines are the linear regression fits. Averaged seasonal-mean TOC (DU) and seasonal linear increase (\%/year) computed for the 1995-2001 period are displayed on the left part of each plot.

Table 3. Annual and seasonal mean of TOC (DU), and corresponding short-term trends (\%/year) for the entire troposphere and for the boundary layer $(B L, 0-2 \mathrm{~km}$ altitude), mid troposphere $(M T, 2-8 \mathrm{~km}$ altitude) and upper troposphere (UT, $8 \mathrm{~km}$ altitude to the dynamical tropopause $D T$ ) over New York, Paris, Frankfurt and Japan.

\begin{tabular}{|c|c|c|c|c|c|c|c|c|c|c|c|}
\hline & \multicolumn{2}{|c|}{ Annual } & \multicolumn{2}{|c|}{ Spring } & \multicolumn{2}{|c|}{ Summer } & \multicolumn{2}{|c|}{ Fall } & \multicolumn{2}{|c|}{ Winter } \\
\hline & & $\mathrm{DU}$ & $\% /$ year & $\mathrm{DU}$ & $\% /$ year & $\mathrm{DU}$ & $\% /$ year & $\mathrm{DU}$ & $\% /$ year & DU & $\% /$ year \\
\hline \multirow{4}{*}{$\begin{array}{c}\text { New York } \\
2631 \text { profiles }\end{array}$} & TOC & 30.3 & 1.1 & 33.4 & 1.5 & 37.8 & 0.0 & 26.8 & 0.8 & 24.0 & 1.9 \\
\hline & TOC in BL & 7.2 & 0.4 & 8.3 & 1.2 & 9.4 & -1.2 & 6.2 & 1.2 & 5.4 & 3.9 \\
\hline & TOC in MT & 17.9 & 1.2 & 20.0 & 1.2 & 20.3 & 0.6 & 16.2 & 1.0 & 15.6 & 2.0 \\
\hline & TOC in UT & 5.5 & 1.3 & 5.7 & 1.6 & 8.1 & 0.1 & 4.8 & -0.1 & 3.8 & -0.7 \\
\hline \multirow{4}{*}{$\begin{array}{c}\text { Paris } \\
3308 \text { profiles }\end{array}$} & TOC & 29.5 & 0.9 & 32.5 & 0.5 & 34.3 & 0.2 & 26.2 & 0.4 & 25.3 & 2.0 \\
\hline & TOC in BL & 6.8 & 0.9 & 7.9 & 0.3 & 7.8 & 0.3 & 5.8 & 0.6 & 5.8 & 3.1 \\
\hline & $\mathrm{TOC}$ in $\mathrm{MT}$ & 17.7 & 1.5 & 19.5 & 1.4 & 20.0 & 0.4 & 16.0 & 0.7 & 15.5 & 1.8 \\
\hline & TOC in UT & 5.2 & -0.1 & 5.5 & -0.9 & 6.6 & -0.4 & 4.6 & -0.2 & 4.2 & 1.9 \\
\hline \multirow{4}{*}{$\begin{array}{c}\text { Frankfurt } \\
6338 \text { profiles }\end{array}$} & TOC & 28.5 & 0.7 & 32.0 & 1.3 & 34.0 & 0.0 & 25.1 & 0.3 & 23.9 & 2.0 \\
\hline & TOC in BL & 6.2 & 0.3 & 7.5 & 0.5 & 7.7 & -0.2 & 5.1 & 0.7 & 5.0 & 3.3 \\
\hline & $\mathrm{TOC}$ in $\mathrm{MT}$ & 17.7 & 0.7 & 19.6 & 1.5 & 20.3 & 0.0 & 16.0 & 0.3 & 15.3 & 1.7 \\
\hline & TOC in UT & 4.9 & 0.8 & 5.3 & 1.2 & 6.2 & 0.2 & 4.2 & 0.0 & 4.0 & 1.7 \\
\hline \multirow{4}{*}{$\begin{array}{c}\text { Japan } \\
1899 \text { profiles }\end{array}$} & TOC & 30.2 & 0.8 & 36.1 & 0.9 & 31.5 & 0.1 & 27.5 & 0.8 & 26.4 & 1.0 \\
\hline & TOC in BL & 7.4 & -0.1 & 9.5 & 0.5 & 6.4 & 0.1 & 6.6 & 0.3 & 7.1 & 0.3 \\
\hline & TOC in MT & 17.8 & 0.8 & 21.3 & 1.0 & 17.8 & 0.1 & 16.1 & 1.0 & 16.4 & 1.0 \\
\hline & TOC in UT & 5.4 & 1.0 & 5.9 & -0.4 & 7.2 & 0.3 & 5.0 & 1.1 & 3.5 & 3.7 \\
\hline
\end{tabular}


The results presented above agree well with other results found in analyses of long-term series of ozone and cited in the introduction. In particular, trends in the short-term ranging from 0.7 to $1.1 \%$ /year for TOC (New York, Frankfurt and Japan) are in good agreement with the longer-term positive trend of 0.7 to $1.4 \%$ /year over Central Europe reported by Weiss et al. (2001) with ozonesonde data. Further comparisons of our results with those by Naja et al. (2003) are of interest. Using the residence times of air masses over Central Europe (computed from 10-day backward trajectories), Naja et al. (2003) analyze the Hohenpeissenberg and Payerne ozonesonde dataset and classify ozone observations associated with central European residence times of 4-6 days as "photochemically aged" ozone. It is shown that, in the range of 1-6 days of residence time, on average and in summer, the mixing ratio of the latter class of ozone increases at a rate of $2 \mathrm{ppbv}$ per day of residence time. Then, by extrapolation to zero days of residence time (using a statistical regression model), the authors build a "background" ozone value which is supposed to represent Atlantic air masses not influenced by European emissions. Although there is no consideration of residence time of air masses over continents in our study, three points of agreement with the findings of Naja et al. (2003) may be found. First, Naja et al. (2003) show that the "photochemically aged" ozone is maximum in summer, minimum in winter, and has been experiencing a substantial decrease in the planetary boundary layer in summertime since the 1990s in agreement with temporal variations of Central European $\mathrm{NO}_{\mathrm{x}}$ emissions. This is in good agreement with the negative trends of TOC in the boundary layer in summertime for New York and Frankfurt reported here (see Table 3). Note that further extension of this work would need to consider the top of the boundary layer, the importance of the diurnal cycle of the boundary layer and of the airport position relative to its associated urban area, which is out of the scope of the present paper. Second, Naja et al. (2003) show positive trends of ozone in "background' and in "photochemically aged" air in winter. It is in good agreement with the consistent positive trends found in wintertime and for the full tropospheric column at the four MOZAIC stations (except for New York in the upper troposphere, see Table 3). Third, Naja et al. (2003) show that "background" ozone in the planetary boundary layer and in the free troposphere has a broad maximum extending from late spring to summer, has a minimum in winter and is experiencing increasing influences of emissions from North America and Eastern Asia. The importance of background pollution and intercontinental transport has been suggested by many other authors (e.g. Berntsen et al., 1996; Jacob et al., 1999; Wild and Akimoto, 2001). The common behaviour of yearly seasonal mean TOC at the four MOZAIC stations (see Fig. 12) is strongly suggestive of a consistent influence of background pollution transported by the general circulation. Therefore, station-to-station comparisons and links with the variations of the general circulations patterns are now discussed.

\subsection{General circulation patterns}

The North Atlantic Oscillation (NAO) is one of the most dominant and regular patterns of atmospheric circulation variability from the United-States to Siberia and from the Arctic to subtropical Atlantic (Wallace and Gutzler, 1981; Barnston and Livezey, 1987). It takes the form of a dipole anomaly in the surface pressure field between Iceland and the Azores. Here, we use the NAO index defined as the difference of normalized sea level pressure between Lisbon, Portugal and Reykjavik, Island (Hurrell, 1995). At the hemispheric scale, geopotential anomalies ranging from the surface to the stratosphere are dominated by a mode of variability known as the Northern Annular Mode (NAM) also called the Arctic Oscillation (Baldwin and Dunkerton, 1999). In order to incorporate the Japanese MOZAIC stations in our investigation we also considered NAM, which has a broader centre of action than NAO in the northern hemisphere. We used monthly-mean mid-tropospheric $(500 \mathrm{hPa})$ NAM indices provided by M. Baldwin (http://www.nwra. com/resumes/Baldwin/nam.html). Positive trends of NAO and $\mathrm{AO}$ in recent decades suggest that circulation changes may contribute to the observed winter trends of total (stratospheric and tropospheric) ozone (Appenzeller et al., 2000; Thomson et al., 2000; Brönniman et al., 2000).

The issue of the influence of general circulation patterns is now discussed with the aid of TOC anomalies and indices of the general circulation. With regard to relationships between NAO/NAM and TOC anomalies, two distinct effects need to be considered. NAO/NAM variability is associated with geographical tropopause pressure patterns and with typical tropospheric transport pathways. For the first effect, Appenzeller et al. (2000) have shown that wintertime tropopause pressures are strongly correlated with a distinct geographical pattern of NAO over a large Atlantic sector, e.g. lower tropopause over Iceland for positive NAO phases as opposed to higher tropopause over Europe in positive NAO phases, and vice versa. This finding has been confirmed in a companion study (Thouret et al., 2006). For the second effect, the tropospheric ozone distribution is influenced by remote sources via long-range transport, which is itself influenced by NAO/NAM inter-annual variations. Over the Atlantic, the Azores high is shifted eastward by about $30^{\circ}$ of longitude for the positive phase of NAO compared to the negative phase and the westerlies are reinforced (Cassou et al., 2004). Then, a faster and more zonal flow is channelled towards western Europe during positive NAO phases and favours the transport of anthropogenic pollution from North America to Europe (see Fig. 3ab in Cassou et al., 2004 and Fig. 1 in Creilson et al., 2003). In consequence, and for the example of the Frankfurt station, NAO positive phases would be associated with positive anomalies of TOC built by an increase of the background tropospheric ozone. Note that $\mathrm{Li}$ et al. (2002) have observed that, when the spring NAO is positive, there is an increase in surface ozone at Mace Head Ireland, and 

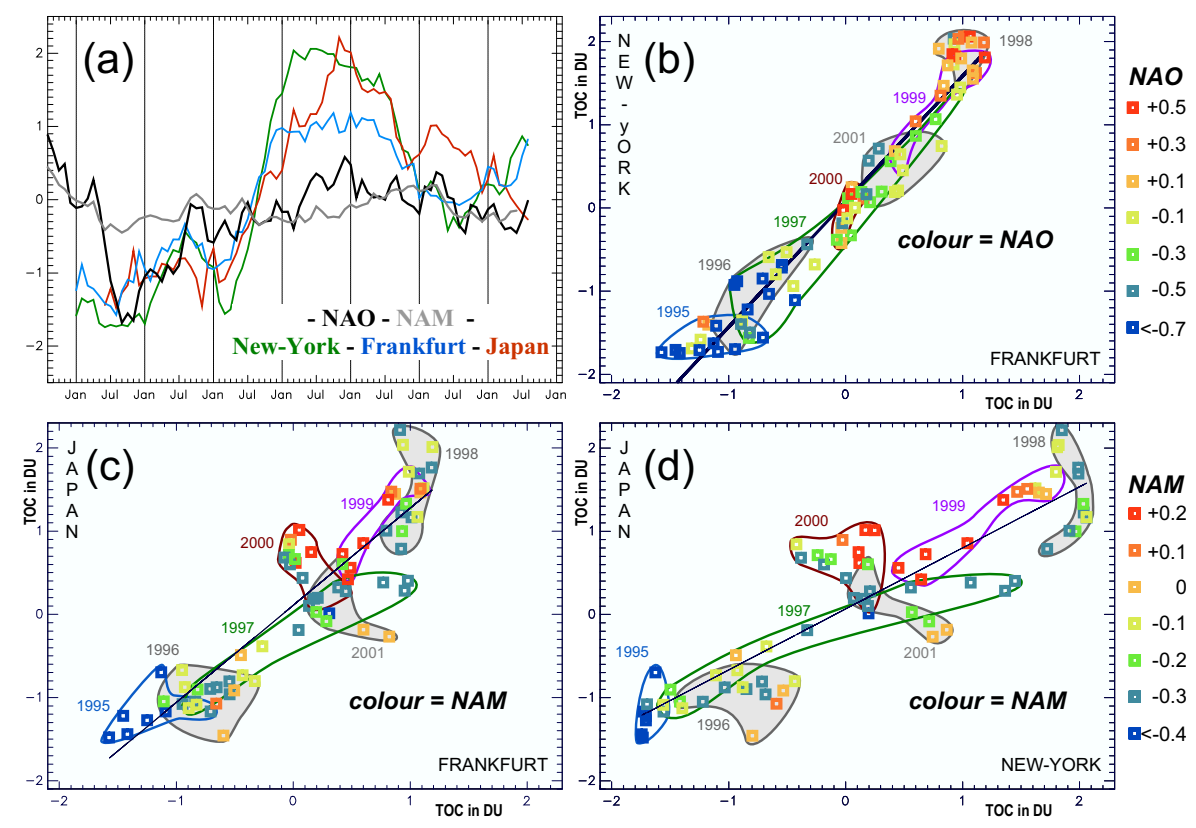

Fig. 13. (a): Time series from 1995 to 2001 of monthly TOC anomalies (DU) in New York (green line), Frankfurt (blue line) and Japan (red line) and of indices for NAO (black lines) and NAM (grey line). (b): Monthly TOC anomalies (DU) in New York versus monthly TOC anomalies (DU) in Frankfurt. Months are symbolized by squares. A coloured line encircles months of one year. The colour of each square is coded with the NAO index scaled regularly in 7 classes between -0.7 and 0.5 as given on the right part of the figure. The black line indicates the linear regression that best fits inter-station TOC anomalies (see Table 4). (c): as for (b) but for Japan versus Frankfurt and for the NAM index at $500 \mathrm{hPa}$. The colour of each square is coded with the NAM index scaled regularly in 7 classes between -0.4 and 0.2 as given on the right part of the figure. (d): as for (c) but for Japan versus New York.

that the transport over the Atlantic occurs not only in the free troposphere but also in the boundary layer.

NAO and NAM display considerable monthly and interannual variability (Hurrell, 1995). Their effects reach the highest point during wintertime but have been observed at all seasons. In the construction of time series of monthly TOC anomalies (Fig. 13a), each monthly TOC is deseasonalized by subtracting its annual-mean value (Fig. 8). To lessen the monthly variability and to capture the extra-seasonal signal shown on Fig. 12, we smooth the time series with a running window of \pm 6 months. The good overall coherence of all parameters over four major periods is striking. The period 1995-1996 shows negative TOC anomalies and negative NAO/NAM indices. It is followed by a transition year in 1997. Then comes the 1998-1999 period with positive TOC anomalies and positive NAO/NAM indices. Finally, there is the last period 2000-2001 during which parameters show less mutual coherence and a gradual transition to negative values. Note that the most important information of Fig. 13a, i.e. the transition from a period of negative TOC anomalies to a period of positive anomalies, is only brought about by the contribution of the mid troposphere (not shown). Monthly time series of the contributions of the boundary layer and the upper troposphere do not show up this transition, which suggests that the mid-tropospheric long-range transport of ozone may be the dominant process. Figure 13b shows the plot of monthly TOC anomalies in Frankfurt versus in New York, symbols are colour-coded with NAO indices. There is a strong relationship between TOC anomalies of the two stations, which is confirmed by a very high correlation factor $(r=0.97$, see Table 4$)$. This correlation factor is even higher than the positive correlation factor between TOC anomalies at each station and NAO indices $(r=0.66$ for the two stations). The very high positive correlation factor between TOC anomalies at the two stations reinforces the suggestion that the long-range mid-tropospheric transport is a dominant process that establishes links between TOC anomalies whether the NAO phases are positive or negative. On the hemispheric scale with the Japanese stations included, the role of transport may be more difficult to assess as suggested by the lessening of the correlation between TOC anomalies and NAM indices (Figs. 13c and d and Table 4). Now, let us consider the positive anomaly that has been defined from autumn 1997 to summer 1999 at all stations (Fig. 12) in the present 7-year dataset. Such an anomaly makes a strong contribution to the common behaviour of TOC related parameters, i.e. multi-station positive short-term trends, multistation positive correlations with NAO/NAM variations, and inter-station correlated anomalies. The winter of 1997-1998, marked by a record-breaking El Nino event, was the second 
Table 4. Parameters deduced from linear regression fit between TOC anomalies (noted $T O C^{\prime}$ ) themselves and between TOC anomalies and NAO or NAM indices over Frankfurt, New York and Japan (see Fig. 13). a and b are parameters of the linear regression fit, $\mathrm{r}$ is the correlation factor and $\sigma$ the standard deviation.

\begin{tabular}{lcccc}
\hline$T O C^{\prime} / T O C^{\prime}$ & $\mathrm{a}$ & $\mathrm{b}$ & $r$ & $\sigma$ \\
\hline Frankfurt-New York & 1.51 & 0.08 & 0.97 & 0.31 \\
Frankfurt-Japan & 1.17 & 0.11 & 0.89 & 0.47 \\
New York-Japan & 0.73 & 0.07 & 0.89 & 0.48 \\
\hline$T O C^{\prime} / N A O$ & $\mathrm{a}$ & $\mathrm{b}$ & $r$ & $\sigma$ \\
\hline Frankfurt & 0.41 & -0.26 & 0.66 & 0.38 \\
New York & 0.26 & -0.28 & 0.66 & 0.38 \\
\hline$T O C^{\prime} / N A M$ & $\mathrm{a}$ & $\mathrm{b}$ & $r$ & $\sigma$ \\
\hline Japan & 0.05 & -0.16 & 0.33 & 0.16 \\
\hline
\end{tabular}

warmest winter since 1895. Global temperatures in 1998 were the warmest in the past 119 years and the previous record was set in 1997 (see the Annual Review on climate of 1998 on the NOOA web site ${ }^{2}$ ). These warmer conditions may have globally favoured the photochemical production of ozone in the troposphere, which, coupled with the transition towards positive NAO/NAM indices, may have also favoured the long-range transport of higher background ozone concentrations. Whether or not the transition of negative to positive NAO phases in this period could be a response to anthropogenic forcing, as suggested by some model scenario experiments in which enhanced greenhouse gas concentrations are prescribed (Ulbrich and Christoph, 1999), or may be better understood in terms of an intrinsic dynamical property of the North Atlantic atmosphere (Cassou et al., 2004) is outside the scope of the present study.

\section{Conclusions}

We have investigated climatological and inter-annual variability aspects of ozone vertical profiles obtained at four stations, Frankfurt (Germany), Paris (France), New York (USA) and the cluster of Tokyo, Nagoya and Osaka (Japan), by commercial aircraft participating in the MOZAIC programme from August 1994 to February 2002. This database of several thousands of vertical profiles constitutes one of the most interesting datasets currently available with regard to research issues on the tropospheric ozone budget and recent shortterm trends. The study focuses on the analysis of two vertical integrated quantities in the troposphere, i.e. the Tropospheric Ozone Column (TOC), which is the vertical integration of ozone from the ground to the dynamical tropopause, and the

\footnotetext{
${ }^{2}$ http://lwf.ncdc.noaa.gov/oa/climate/research/1998/ann/ann98. html)
}

Stratospheric Intrusion Column (SIC), which is the vertical integration of stratospheric-origin ozone throughout the troposphere. Commercial aircraft generally fly in the altitude range $9-12 \mathrm{~km}$, so ascent and descent profiles at airports do not systematically include the tropopause region. Taking into account the interest of working on a large number of vertical profiles and the necessity of having profiles in the full depth of the troposphere (to compute the integrated quantities), our strategy has been to fill up unexplored parts of the vertical profiles as far as possible with seasonal climatological profiles. This avoids biasing the results towards meteorological situations for which the tropopause is systematically low. The impact that the filling-up process may have on the investigation of short-term trends by introducing a component that is time-independent in the dataset is limited to the summertime uppermost troposphere in New York and Japan.

The climatological analysis shows that the TOC seasonal cycle ranges from a wintertime minimum of about 22-25 DU at all four stations to a spring-summer maximum of about 35 DU in Frankfurt and Paris, and 38 DU in New York. Over Japan, the maximum occurs in spring because of the earlier springtime sun, then the invasion of monsoon air masses in the boundary layer and in the mid troposphere steeply diminishes the summertime TOC. Boundary layer contributions to TOC are 10\% higher in New York than in Frankfurt and Paris during spring and summer, and are $10 \%$ higher in Japan than in New York, Frankfurt and Paris during autumn and early spring. Local and remote anthropogenic emissions and biomass burning over upstream regions of Asia may be responsible for larger low- and mid-tropospheric contributions to TOC over Japan throughout the year except during the summer-monsoon season.

A simple Lagrangian analysis based on 24-hour backward trajectories of air masses has shown that the contribution of SIC to TOC exhibits a springtime maximum of about $3 \mathrm{DU}$ and a minimum in autumn of about $2 \mathrm{DU}$, which roughly corresponds to $10 \%$ of stratospheric-origin ozone coming into the troposphere throughout the year. As this preliminary analysis minimizes the stratospheric source and confirms the important role of stratosphere-troposphere exchange in the tropospheric ozone budget, it encourages us to further develop the Lagrangian approach and investigate the issue more deeply with the MOZAIC dataset.

The investigation of the short-term trends in the tropospheric ozone column over the period 1995-2001 has shown a linear increase of $0.7 \%$ year in Frankfurt, $0.8 \%$ year in Japan, 1.1\%/year in New York and 1.6\%/year in Paris for the reduced period of 1995-1999. This is in agreement with longer-term positive trend of 0.7 to $1.4 \%$ /year over Central Europe reported by Weiss et al. (2001) with ozonesonde data. Results show that essential ingredients of the positive short-term trends are the continuous increase of wintertime TOC from 1996 to 1999 and the contributions of the mid troposphere whatever the season. Slightly negative shortterm trends in the contributions of the boundary layer to 
TOC in New York and Frankfurt may be an indication of decreasing $\mathrm{NO}_{\mathrm{x}}$ emissions. Summertime ozone does not seem to contribute to the positive short-term trends, though relatively higher summertime TOC were recorded in 1998 for New York, Paris and Frankfurt and in 1999 for New York and Japan. Some considerations involving possible effects of large-scale circulation pattern variability like the North Atlantic Oscillation and the Northern Annular mode have been discussed. The transition from a period of negative TOC anomalies before 1997 to a period of positive TOC anomalies in 1998-1999 comes with a shift from negative to positive phases of the North Atlantic Oscillation which seems to be a determining factor in the positive short-term trends observed in New York, Frankfurt and Paris.

\section{Appendix A}

\section{Computation of the Tropospheric Ozone Column (TOC)}

For a volume of gas $V$ measured at pressure $P$ and temperature $T$, it is possible to define the volume $V_{s}$ it would occupt at standard pressure $P_{S}=101325 \mathrm{~Pa}$ and standard temperature $T_{s}=273.15 \mathrm{~K}$ by referring to the Ideal Gas Law:

$$
\frac{P \cdot V}{T}=\frac{P_{s} \cdot V_{s}}{T_{S}}
$$

which can also be written as:

$\rho=\rho_{s} \cdot \frac{T_{s}}{T} \cdot \frac{P}{P_{s}}$

where $\rho$ and $\rho_{s}$ are the density and the standard density of air.

Then, using Eq. (A1), if we apply the definition of partial pressure, we find the ozone number density (molecules per unit volume, $\left.\rho_{\left(O_{3}\right)}\right)$ with:

$\rho_{\left(O_{3}\right)}=\frac{N_{A}}{V} \cdot \frac{T_{s}}{T} \cdot \frac{P_{p\left(O_{3}\right)}}{P_{S}}$

where, $N_{A}$ is Avogadro's number $\left(N_{A}=6,022 \cdot 10^{23}\right)$ and $V$ the volume of air $(V=22,41)$. The ratio $N_{A} / V$ is the number of molecules per unit volume of air, i.e. Loschmit number $\left(\rho_{s}\right)$.

In Eq. (A2), $T$ is the temperature at the pressure $P$ of MOZAIC ozone measurement and $P_{p\left(\mathrm{O}_{3}\right)}$ the corresponding partial pressure deduced from the ozone mixing ratio $r_{m}\left(\mathrm{O}_{3}\right)$ given in ppbv, with the following relation:

$P_{p\left(O_{3}\right)}=r_{m\left(O_{3}\right)} \cdot P$

Replacing constant values in Eq. (A2), we find, in molecules $\mathrm{cm}^{-3}$ :

$\rho_{\left(\mathrm{O}_{3}\right)}=7,2425 \cdot 10^{16} \cdot \frac{P_{p\left(\mathrm{O}_{3}\right)}}{T}$
The ozone thickness of each $150 \mathrm{~m}$ depth layer of the atmosphere $(h=150 \mathrm{~m})$, expressed in DU, will be called the Ozone Layer Thickness $(O L T)$. We will used $O L T$ to evaluate the MOZAIC Ozone Column $(M O C)$ in DU, which is the integration of $O L T$ over the MOZAIC vertical column (Fig. 2).

To obtain $O L T$ in DU, we introduce, in Eq. (A4), the depth of the layer $(h=150 \mathrm{~m})$ and the conversion factor from molecules $\mathrm{cm}^{-2}$ to DU:

$O L T=\frac{7,2425 \cdot 10^{16}}{2,6861 \cdot 10^{16}} \cdot \frac{P_{p\left(O_{3}\right)}}{T} \cdot h \cdot 10^{2}$

and combining Eqs. (A3) and (A5) we find OLT:

$O L T=4,044 \cdot 10^{-5} \cdot \frac{r_{m\left(O_{3}\right)} \cdot P}{T}$

In Eq. (A6), $P$ is in $\mathrm{Pa}, r_{m\left(\mathrm{O}_{3}\right)}$ in ppbv, $T$ in $\mathrm{K}$ and $O L T$ in DU/150 m.

The tropospheric Ozone Column (TOC, expressed in DU) is the integration of $O L T$ from ground up to the dynamical tropopause $(D T)$ :

$T O C=\sum_{\text {ground }}^{D T} O L T$

Acknowledgements. The authors acknowledge the strong support the European Commission (EVK2-CT1999-00015), Airbus and the airlines (Lufthansa, Air France, Austrian and former Sabena who have been carrying the MOZAIC instrumentation free of charge since 1994).

We warmly thank A. Marenco, founder of the MOZAIC programme, for all his support to this study.

We acknowledge J. W. Hurrell and M. P. Baldwin for NAO and NAM indices, respectively.

Edited by: P. Haynes

\section{References}

Andrews, D. G., Holton, J. R., and Leovy, C. B.: Middle Atmosphere Dynamics, Academic Press, San Diego, California, USA, 489 pp, 1987.

Appenzeller, C., Holton, J. R., and Rosenlof, K. H.: Seasonal variation of mass transport across the tropopause, J. Geophys. Res., 101(D10), 15 071-15 078, doi:10.1029/96JD00821, 1996.

Appenzeller, C., Weiss, A. K., and Staehelin, J.: North Atlantic Oscillation modulates total ozone winter trends, Geophys. Res. Lett., 27, 1131-1134, 2000.

Baldwin, M. P. and Dunkerton, T. J.: Propagation of the Arctic oscillation from the stratosphere to the troposphere, J. Geophys. Res., 104(D24), 30 937-30 946, 1999.

Barnston, A. G. and Livezey, R. E.: Classification, seasonality, and persistence of low-frequency atmospheric circulation patterns, Mon. Wea. Rev., 115, 1083-1126, 1987. 
Berntsen, T., Isaksen, I. S. A., Wang, W., and Liang, X.: Impacts of increased anthropogenic emissions in Asia on tropospheric ozone and climate, Tellus, 48B, 13-32, 1996.

Bethan, S., Vaughan, G., and Reid, S. J.: A comparison of ozone and thermal tropopause heights and the impact of tropopause definition on quantifying the ozone content of the troposphere, Q. J. R. Meteorol. Soc., 122, 929-944, 1996.

Bithell, M., Vaughan, G., and Gray, L. J.: Persistence of stratospheric ozone layers in the troposphere, Atmos. Environ., 34(16), 2563-2570, 2000.

Brönnimann, S., Luterbacher, J., Schnutz, C., Wanner, H., and Staehelin, J.: Variability of total ozone at Arosa, Switzerland, since 1931 related to atmospheric circulation indices, Geophys. Res. Lett., 27 (No. 15), 2213-2216, 2000.

Browell, E. V., Danielsen, E. F., Ismail, S., Gregory, G. L., and Beck, S. M.: Tropopause fold structure determined from airborne lidar and in-situ measurements, J. Geophys. Res., 92(D2), 21122120, 1987.

Cassou, C., Terray, L., Hurrell, J. W., and Deser, C.: North Atlantic winter climate regimes: spatial asymmetry, stationarity with time, and oceanic forcing, J. Climate, 17, 1055-1068, 2004.

Chameides, W. L. and Walker, J. C. G.: A photochemical theory of tropospheric ozone, J. Geophys. Res., 78, 8751-8760, 1973.

Chameides, W. L. and Walker, J. C. G.: A time-dependant photochemical model for ozone near the ground, J. Geophys. Res., 81(3), 413-420, 1976.

Chatfield, R. and Harrison, H.: Ozone in remote troposphere : mixing versus photochemistry, J. Geophys. Res., 81(3), 421-423, 1976.

Creilson, J. K., Fishman, J., and Wozniak, A. E.: Intercontinental transport of tropospheric ozone: a study of its seasonal variability across the North Atlantic utilizing tropospheric ozone residuals and its relationship to the North Atlantic Oscillation, Atmos. Chem. Phys., 3, 2053-2066, 2003.

Crutzen, P. J.: A discussion of the chemistry of some minor constituents in the stratosphere and troposphere, Pure Appl. Geophys., 106, 1385-1399, 1973.

Crutzen, P. J.: Photochemical reactions initiated by and influencing ozone in unpolluted tropospheric air, Tellus, 26, 47-56, 1974.

Danielsen, E. F.: Stratospheric-tropospheric exchange based on radioactivity, ozone and potential vorticity, J. Atmos. Sci., 25, 502528, 1968.

Danielsen, E. F., Hiskind, R. S, Gaines, S. E., Sachse, G. W., Gregory, G. L., and Hill, G. F.: Three-dimensional analysis of potential vorticity associated with tropopause folds and observed variations of ozone and carbon monoxide, J. Geophys. Res., 92, 2103-2111, 1987.

Ertel, H.: Ein neuer hydrodynamischer Wirbelsatz, Meteorologishe Zeitschrift, 59, 277-281, 1942.

Fabian, P.: A Photochemical theory of tropospheric ozone by Chameides, W. and Walker, J. C. G. - Comments, J. Geophys. Res., 79(D27), 4124-4125, 1974.

Feister, U. and Warmbt, W.: Long-term measurements of surface ozone in the German-Democratic-Republic, J. Atmos. Chem., 5, $1,1-21,1987$.

Forster de, P. M. and Shine, K. P.: Radiative forcing and temperature trends from stratospheric ozone changes, J. Geophys. Res., 102(D9), 10 841-10 855 (96JD03510), 1997.

Gouget, H., Vaughan, G., Marenco, A., and Smit, H. G. J.: De- cay of a cut-off low and contribution to stratosphere-troposphere exchange, Q. J. R. Meteorol. Soc., 126, 1117-1141, 2000.

Harris, N. R. P., Ancellet, G., Bishop, L., Hofmann, D. J., Kerr, J. B., McPeters, R. D., Prendez, M., Randel, W. J., Staehelin, J., Subbaraya, B. H., Volz-Thomas, A., Zawodny, J., and Zerefos, C. S.:, Trends in stratospheric and free tropospheric ozone, J. Geophys. Res., 102(D1), 1571-1590, 1997.

Hoerling, M. P., Schaack, T. K., and Lenzen, A. J.:, Global Objective Tropopause Analysis, Mon. Wea. Rev., 119(8), 1816-1831, 1991.

Hoinka, K. P.: Statistics of the global tropopause pressure, Mon. Wea. Rev., 126 (12), 3303-3325, 1998.

Holton, J. R., Haynes, P. H., McIntyre, M. E., Douglass, A. R., Rood, R. B., and Pfister, L.: Stratosphere-troposphere exchange, Rev. Geophy., 33(4), 403-439, 1995.

Hoskins, B. J., McIntyre, M. E., and Robertson, A. W.: On the use and significance of isentropic potential vorticity maps, Q. J. R. Meteorol. Soc. 111, 877-946, 1985.

Hurrell, J. W.: Decadal trends in the North Atlantic Oscillation: Regional temperatures and precipitation, Sciences, 269, 676-679, 1995.

Jacob, D. J., Logan, J. A., and Murti, P. P.: Effects of rising Asian emissions on surface ozone in the United States, Geophys. Res. Lett., 26, 2175-2178, 1999.

James, P., Stohl, A., Forster, C., Eckhardt, S., Seibert, P., and Frank, A.: A 15-years climatology of stratosphere-troposphere exchanges with a Lagrangian particle dispersion model, part B, Mean climate and seasonal variability, J. Geophys. Res., 108(D12), 8522, doi:10.10129/2002JD002639, 2003.

Junge, C. E.: Global ozone budget and exchange between stratosphere and troposphere, Tellus, 14, 363-377, 1962.

Lamarque, J. F. and Hess, P. G.: Cross-tropopause mass exchange and potential vorticity budget in a simulated tropopause folding, J. Atmos. Sci., 51, 2246-2269, 1994.

Li, Q., Jacob, D. J., Bey, I., Palmer, P. I., Duncan, B. N., Field, B. D., Martin, R. V., Fiore, A. M., Yantosca, R. M., Parrish, D. D., Simmonds, P. G., and Oltmans, S. J.: Transatlantic transport of pollution and its effects on surface ozone in Europe and North America, J. Geophys. Res., 107, 4166, doi:10.129/2001JD001422, 2002.

Logan, J. A.: Tropospheric ozone: Seasonal behaviour, trends and anthropogenic influences, J. Geophys. Res., 90(D6), $10463-$ $10482,1985$.

Logan, J. A.: Trends in the vertical distribution of ozone: an analysis of ozonesondes data, J. Geophys. Res., 99(D12), $25553-$ 25 585, 1994.

Logan, J. A.: An analysis of ozonesonde data for the troposphere: Recommendations for testing 3-D models, and development of a gridded climatology for tropospheric ozone, J. Geophys. Res., 104, 16 115-16 149, 1999.

Marenco, A., Gouget, H., Nédélec, P., Pagés, J. P., and Karcher, F.: Evidence of a long-term increase in tropospheric ozone from Pic du Midi data series. Consequences: Positive radiative forcing, J. Geophys. Res., 99, 16617-16632, 1994.

Marenco, A., Thouret, V., Nédélec, P., Smit, H., Helten, M., Kley, D., Karcher, F., Simon, P., Law, K., Pyle, J., Poschmann, G., Von Wrede, R., Hume, C., and Cook, T.: Measurement of ozone and water vapor by Airbus in-service aircraft: The MOZAIC airborne program, An overview, J. Geophys. Res., 103(25), 631- 
642, 1998.

Nédélec, P., Cammas, J. P., and Thouret, V.: An improved infrared carbon monoxide analyser for routine measurements aboard commercial Airbus aircraft: technical validation and first scientific results of the MOZAIC III program, Atmos. Chem. Phys., 3, 1551-1564, 2003.

Naja, M., Akimoto, H., and Staehelin, J.: Ozone in background and photochemically aged air over Central Europe: Analysis of long-term ozonesonde data from Hohenpeissenberg and Payerne, J. Geophys. Res., 108(D2), 4063, doi:10.1029/2002JD002477, 2003.

Oltmans, S. J., Lefohn, A. S., Scheel, H. E., Harris, J. M., Levy, H., Galbally, I. E., Brunke, E.-G., Meyer, C. P., Lathrop, J. A., Johnson, B. J., Shadwick, D. S., Cuevas, E., Schmidlin, F. J., Tarasick, D. W., Claude, H., Kerr, J. B., Uchino, O., and Mohnen, V.: Trends of ozone in troposphere, Geophys. Res. Lett., 25 (No. 2), 139-142, 1998.

Regener, V. H.: Vertical flux of atmospheric ozone, J. Geophys. Res., 62, 221-228, 1957.

Roelofs, G. J. and Lelieveld, J.: Model study of the influence of cross-tropopause ozone transport on tropospheric ozone levels, Tellus, B49, 38-55, 1997.

Sprenger, M., Croci Maspoli, M., and Wernli, H.: Tropopause folds and cross-tropopause transport: A global investigation based upon 60 level ECMWF analyses for the time period March 2000 till February 2001, J. Geophys. Res., 108(D12), doi:10.10292002/JD002587, 2003.

Staehelin, J. and Schmid, W.: Trend analysis of tropospheric ozone concentrations utilizing the 20-year data set of ozone balloon soundings over Payerne (Switzerland), Atmos. Environ., 25A, 1739-1749, 1991.

Staehelin, J., Thudium, J., Buehler, R., Volz-Thomas, A., and Graber, W.: Trends in surface ozone concentrations at Arosa, Switzerland, Atmos. Environ., 28, 75-87, 1994.

Stohl, A., Spictinger-Rakowsky, N., Bonasoni, P., Feldman, H., Memmesheimer, M., Scheel, H. E., Trickl, T., Hubener, S., Ringer, W., and Mandl, M.: The influence of stratospheric intrusions on alpine ozone concentrations, Atmos. Environ., 34, 1323-1354, 2000.

Stohl, A.: A one-year Lagrangian "climatology" of airstreams in the northern Hemisphere troposphere and lowermost stratosphere, J. Geophys. Res., 106, 7263-7279, 2001.

Stohl, A., Bonasoni, P., Cristofanelli, P., et al.: Stratospheretroposphere exchange: A review and what we have learned from STACCATO, J. Geophys. Res., 108(D12), 8516, doi:10.1029/2002JD002490, 2003.

Tarasick, D. W., Fioletov, V. E., Wardle, D. I., Kerr, J. B., and Davies, J.: Changes in the vertical distribution of ozone over Canada from ozonesondes: 1980-2001, J. Geophys. Res., 110(D2), D02304, doi:10.10129/2004JD004643, 2005.
Thomson, D. W., Wallace, J. J. M., and Hegerl, G. C.: Annular modes in the extratropical circulation. Part II: Trends, J. Climate, 13, 1018-1038, 2001.

Thouret, V., Marenco, A., Nédélec, P., and Grouhel, C.: Ozone climatologies at $9-12 \mathrm{~km}$ altitude as seen by the MOZAIC airborne program between September 1994 and August 1996, J. Geophys. Res., 103(25), 653-679, 1998a.

Thouret, V., Marenco, A., Logan, J. A., Nédélec, P., and Grouhel, C.: Comparisons of ozone measurements from the MOZAIC airborne program and the ozone sounding network at eight locations, J. Geophys. Res., 103(25), 695-720, 1998b.

Thouret, V., Cammas, J.-P., Sauvage, B., Athier, G., Zbinden, R., Nédélec, P., Simon, P., and Karcher, F.: Tropopause referenced ozone climatology and inter-annual variability (1994-2003) from the MOZAIC programme, Atmos. Chem. Phys., 6, 1033-1051, 2006.

Tiao, G. C., Reinsel, G. C., Pedrick, J. H., Allenby, G. M., Mateer, C. L., Miller, A. J., and Deluisi, J. J.: A statistical analysis of ozonesonde data, J. Geophys. Res., 91, 13 121-13 336, 1986.

Ulbrich, U. and Christoph, M.: A shift of the NAO and increasing storm track activity over Europe due to anthropogenic greenhouse gas forcing, Climate Dynamics, 15, 551-559, 1999.

Volz, A. and Kley, D.: Evaluation of the Montsouris series of ozone measurements made in the nineteenth century, Nature, 332, 240242, 1988.

Volz-Thomas, A., Berg, M., Heil, T., Houben, N., Lerner, A., Petrick, W., Raak, D., and Pätz, H.-W.: Measurements of total odd nitrogen $\left(\mathrm{NO}_{\mathrm{y}}\right)$ aboard MOZAIC in-service aircraft: instrument design, operation and performance, Atmos. Chem. Phys., 5, 583595, 2005.

Wallace, J. M. and Gutzler, D. S.: Teleconnections in the geopotential height field during the northern hemisphere winter, Mon. Wea. Rev., 109, 784-812, 1981.

Weiss, A. K., Staehelin, J., Appenzeller, C., and Harris, N. R. P.: Chemical and dynamical contributions to ozone profile trends of the Payerne (Switzerland) balloon soundings, J. Geophys. Res., 106, 22 685-22 694, 2001.

Wernli, H. and Davies, H. C.: A Lagrangian-based analysis of extratropical cyclones, 2, A detailed case study Q. J. R. Meteorol. Soc., 123, 467-489, 1997.

Wernli, H. and Bourqui, M.: A Lagrangian "one-year climatology" of (deep) cross-tropopause exchange in the extratropical northern hemisphere, J. Geophys. Res., 107(D2), 4021, doi:10.10129/2001JD000812, 2002.

Wild, O. and Akimoto, H.: Intercontinental transport of ozone and its precursors in a global 3-D global CTM, J. Geophys. Res., 106, 27 729-27 744, 2001.

World Meteorological Organisation (WMO): Meteorology - A three dimensional science, WMO Bulletin, 6, 134-138, 1957. 